\title{
Predicting the seasonal evolution of southern African summer precipitation in the DePreSys3 prediction system
}

\author{
Paul-Arthur Monerie $^{1}$ (D) Jon Robson ${ }^{1} \cdot$ Buwen Dong $^{1} \cdot$ Bastien Dieppois $^{2,3,4} \cdot$ Benjamin Pohl $^{5} \cdot$ Nick Dunstone $^{6}$
}

Received: 17 August 2018 / Accepted: 31 October 2018 / Published online: 3 November 2018

(c) The Author(s) 2018

\begin{abstract}
We assess the ability of the DePreSys3 prediction system to predict austral summer precipitation (DJF) over southern Africa, defined as the African continent south of $15^{\circ} \mathrm{S}$. DePresys 3 is a high resolution prediction system (at a horizontal resolution of $\sim 60 \mathrm{~km}$ in the atmosphere in mid-latitudes and of the quarter degree in the Ocean) and spans the long period 1959-2016. We find skill in predicting interannual precipitation variability, relative to a long-term trend; the anomaly correlation skill score over southern Africa is greater than 0.45 for the first summer (i.e. lead month 2-4), and 0.37 over Mozambique, Zimbabwe and Zambia for the second summer (i.e. lead month 14-16). The skill is related to the successful prediction of the El-Nino Southern Oscillation (ENSO), and the successful simulation of ENSO teleconnections to southern Africa. However, overall skill is sensitive to the inclusion of strong La-Nina events and also appears to change with forecast epoch. For example, the skill in predicting precipitation over Mozambique is significantly larger for the first summer in the 1990-2016 period, compared to the 1959-1985 period. The difference in skill in predicting interannual precipitation variability over southern Africa in different epochs is consistent with a change in the strength of the observed teleconnections of ENSO. After 1990, and consistent with the increased skill, the observed impact of ENSO appears to strengthen over west Mozambique, in association with changes in ENSO related atmospheric convergence anomalies. However, these apparent changes in teleconnections are not captured by the ensemble-mean predictions using DePreSys3. The changes in the ENSO teleconnection are consistent with a warming over the Indian Ocean and modulation of ENSO properties between the different epochs, but may also be associated with unpredictable atmospheric variability.
\end{abstract}

Keywords Southern African precipitation $\cdot$ ENSO $\cdot$ Seasonal prediction $\cdot$ High resolution climate models

Electronic supplementary material The online version of this article (https://doi.org/10.1007/s00382-018-4526-3) contains supplementary material, which is available to authorized users.

Paul-Arthur Monerie

pmonerie@gmail.com

1 Department of Meteorology, National Centre for Atmospheric Science (NCAS), University of Reading, Reading, UK

2 Centre for Agroecology, Water and Resilience, Coventry University, Coventry, UK

3 School of Geography, Earth and Environmental Sciences, University of Birmingham, Birmingham, UK

4 Department of Oceanography, MARE Institute, University of Cape Town, Cape Town, RSA

5 Centre de Recherches de Climatologie, UMR6282 Biogéosciences, CNRS/Université de Bourgogne Franche Comté, Dijon, France

6 Met Office Hadley Centre, Exeter, UK

\section{Introduction}

Predicting climate for the upcoming season to several decades helps decision makers to adapt policies to near-term climate change (Meehl et al. 2009). The need to anticipate damages due to climate variability is a stressing problem, especially in developing countries, which are more vulnerable to climate hazards. Climate projections are mostly provided by simulations performed with Atmosphere-Ocean General Circulation Models (AOGCM) under the Climate Model Intercomparison Project, phase 5 (CMIP5; Taylor et al. 2012). However, uninitialized predictions have shown limitations in predicting climate on short-time horizons ( $<10$ years) due to uncertainties in simulating internal climate variability, as highlighted by the "hiatus" in globalmean surface temperature rise (Watanabe et al. 2013; Kosaka and Xie 2013; Meehl et al. 2014). Prediction systems are initialised from observations, and provide more 
skilful near-term climate predictions, i.e. from seasonal to decadal timescales (Bellucci et al. 2013; Karspeck et al. 2015; Shaffrey et al. 2017), and narrow such uncertainties.

There is significant skill in initialised climate predictions. For example, there is considerable skill in predicting North Atlantic Sea Surface Temperature (SST) on seasonalto-decadal timescales (Pohlmann et al. 2009; Yeager et al. 2012, 2018; Matei et al. 2012; Doblas-Reyes et al. 2013a; Karspeck et al. 2015; Monerie et al. 2017; Shaffrey et al. 2017; Robson et al. 2017). There is also substantial skill in predicting the El-Niño Southern Oscillation (ENSO) on seasonal (Barnston et al. 2011; Imada et al. 2015) and multi-year timescales (Gonzalez and Goddard 2016) and in predicting the Pacific Decadal Oscillation a few years ahead (Mochizuki et al. 2012; Chikamoto et al. 2013). Although the evidence for improvement over land is weak in decadal predictions (Shaffrey et al. 2017; Yeager et al. 2018), there is significant evidence that improved predictions over land is possible on seasonal timescales (Doblas-Reyes et al. 2013b) due to soil moisture, snow and ice cover initialisation (Douville and Chauvin 2000; van den Hurk et al. 2012; Orsolini et al. 2013; Day et al. 2014). In addition, land Surface Air Temperature (SAT) and precipitation are associated with SST variability, which is better predicted, providing opportunities to improve and predict climate over land. Substantial skill has for instance been shown in predicting Sahel precipitation (Gaetani and Mohino 2013; Mohino et al. 2016; Sheen et al. 2017) and North East Asian temperature Monerie et al. (2017b) due to the remote impacts of the Atlantic Multidecadal variability.

The added value of Ocean initialisation could therefore lead to high skill in seasonal prediction, and in particular for precipitation over southern Africa (here defined as the African continent south of $15^{\circ} \mathrm{S}$ ), where Landman et al. (2001), Reason et al. (2006), Landman and Beraki (2012) and Beraki et al. (2013) have all demonstrated that skill in predicting precipitation is strongly associated with model's ability to predict ENSO events. It has been shown that southern African precipitation is better predicted during El-Niño and LaNiña years than during neutral years (Landman and Beraki 2012). Thus, there is a growing body of evidence showing that initialised climate prediction systems provide valuable skill in predicting regional climate over land, and to their ability to reproduce the remote impact of SST on interannual to interdecadal timescales.

Interannual climate variability over southern Africa is indeed primarily related to ENSO (Ropelewski and Halpert 1987, 1989; Lindesay 1988; Matarira 1990; Mason and Jury 1997; Mason and Goddard 2001; Rouault and Richard 2005; Lyon and Mason 2007; Crétat et al. 2012; Ratna et al. 2013; Ratnam et al. 2014; Malherbe et al. 2016): El-Niño events favour droughts, while La-Niña events favour wet conditions over southern Africa in austral summer. During
El-Nino years, the South Atlantic and Indian subtropical Highs shift northward, hence reducing moisture transport convergence and precipitation over southern Africa (Mason and Jury 1997; Reason and Mulenga 1999; Cook et al. 2004; Rouault and Richard 2005; Reason and Jagadheesha 2005; Vigaud et al. 2009; Crétat et al. 2012; Ratnam et al. 2014; Dieppois et al. 2015). Similarly, the subsidence associated with El-Niño events over southern Africa modulates the strength and location of the Angola Low, a cyclonic circulation associated with low values in surface pressure, over Angola, Namibia and Botswana (Reason and Jagadheesha 2005; Lyon and Mason 2007, 2009; Crétat et al. 2012, 2018; Munday and Washington 2017; Howard and Washington 2018). ENSO events are also associated with an eastward shift of the South Indian Convergence Zone (SICZ; Cook 2000; Ratnam et al. 2014) and the associated synoptic-scale rain-bearing systems that affect southern Africa, e.g. tropical-temperate troughs (TTTs: Fauchereau et al. 2009). These systems are responsible for significant amounts of rainfall during austral summer (Harrison 1984; Crimp et al. 1998; Todd and Washington 1999; Hart et al. 2012, 2013; Macron et al. 2013).

Although many studies show that ENSO is a crucial driver of interannual variability over southern Africa, and a source of skill in seasonal predictions, there remain important questions. For example, given the discussion above, there is a rationale to expect skill in predicting variability in precipitation over southern Africa beyond seasonal timescales owing to the strong remote impact of SST upon interannual precipitation variability over southern Africa, and the relatively high skill in predicting SSTs at interannual time scales, including ENSO (Barnston et al. 2011; Imada et al. 2015). Evidence also suggests that the impact of ENSO on southern African precipitation at the synoptic to interannual timescales is modulated by decadal modes of climate variability (Dyer and Tyson 1977; Tyson 1981; Mason and Jury 1997; Dieppois et al. 2016; Malherbe et al. 2016; Pohl et al. 2018). Furthermore, such a modulation could explain nonstationarities in the impact of ENSO over land (Richard et al. 2000, 2001). Therefore, the quality of predictions of southern African precipitation may depend not only on the period over which they are evaluated, but potentially on a prediction system's ability to simulate the modulation of the ENSO teleconnection on decadal timescales, as has been argued for the predictability of the North Atlantic Oscillation (O'Reilly et al. 2017; Weisheimer et al. 2017). A further motivation comes from the fact that, according to Dieppois et al. (2015), some models perform well in reproducing the remote impact of ENSO on the southern African regional circulation and rainfall through a change of the upper atmospheric circulation. In particular, CMIP5 models differ significantly in their representation of austral summer rainfall amounts over the historical period (Hewitson and Crane 2006; Christensen 
et al. 2007; Nikulin et al. 2012; Dieppois et al. 2015; Munday and Washington 2017).

In order to address the uncertainties we will study predictions made with the UK Met Office Decadal Prediction System version3 (DePreSys3; Dunstone et al. 2016, 2018). Hindcasts from DePreSys3 span a much longer period than other seasonal forecasting data sets (i.e. from 1959 to 2016) and have a large number of members (i.e. 30 for a lead time of up to 17 months). Furthemore, DePreSys3 has significant skill at predicting ENSO up to a year ahead (Dunstone et al. 2016). Therefore, this particular dataset will allow us to more accurately assess skill of southern African precipitation at seasonal and interannual timescales. Specifically, we aim to address the following questions:

- Is DePreSys3 able to predict interannual variability in summer precipitation over southern Africa at seasonal or interannual timescales?

- What are the sources of skill?

- Is the skill significantly dependent upon the forecast validation period?

The paper is structured as follows. The model, data and methodology are described in Sect. 2. Section 3 focuses on the model ability to predict the southern African precipitation. We analyze the source of skill in Sect. 4. A discussion is given in Sect. 5 and a conclusion in Sect. 6.

\section{Data and method}

\subsection{DePreSys3}

DePreSys 3 is a high resolution AOGCM developed at the Met Office (Dunstone et al. 2016, 2018), based on the Hadley Centre Global Environment Model version 3, global coupled configuration v2 (HadGEM3-GC2; Williams et al. 2015). The atmosphere model is the Global Atmospheric version 6.0 of the Met Office Unified Model, ran at the N216 resolution ( $~ 60 \mathrm{~km}$ in mid-latitudes) with 85 vertical levels ensuring a resolved stratosphere. The Ocean model is the Global ocean version 5.0 (Megann et al. 2014), based on the Nucleus for European Models of the Ocean Model (NEMO; Madec 2008). The ocean resolution is run at a quarter degree using the NEMO tripolar grid with 75 vertical levels (the ORCA025L75 grid; Bernard et al. 2006). The sea-ice model is CICE version 4.1 (Hunke and Lipscomb 2004) from the United States Los Alamos National Laboratory and the land surface model is the Joint UK Land Environment Simulator (JULES; Best et al. 2011). The different model components are coupled with OASIS3 (Valcke 2013). For an extended description of the UM-JULES and NEMO-CICE coupling the reader can refer to Walters et al. (2014) and Megann et al. (2014).

Hindcasts are started every year between 1959 and 2015 (i.e. 57 start dates). Thirty ensemble members are initialized on the 1st November of each start date, and are generated using different seeds to a stochastic physics scheme (MacLachlan et al. 2015). Each hindcast lasts for 16 months, and are forced by the historical evolution of external forcings (GHG, aerosols, ozone, solar radiation and volcanoes). After 2005, external forcing is taken from the RCP4.5 scenario, as in the CMIP5 protocol (Taylor et al. 2012). DePreSys3 is full-field initialized by relaxing a coupled integration of HadGEM3GC2 towards gridded observations. Three-dimensional ocean temperature and salinity are relaxed toward the Met Office statistical ocean reanalysis (MOSORA; Smith and Murphy 2007; Smith et al. 2015), the sea-ice concentration is taken from HadISST (Rayner et al. 2003) and the atmosphere model is initialised from ERA-40 before 1979 and ERA-interim atmospheric temperature and winds afterwards (Dee et al. 2011).

\subsection{Observations/reanalysis}

Model skill is evaluated using observations and reanalysis. For precipitation we used the Global Precipitation Climatology Centre (GPCC) version v7 (Schneider et al. 2014). GPCC is available over the long period 1901-present on a $0.5^{\circ} \times 0.5^{\circ}$ latitude-longitude grid. For a large range of atmospheric variables (i.e. SAT, winds, specific humidity, geopotential height, pressure) we used the data from the National Centers for Environmental Prediction (NCEP) reanalysis (R-1; Kanamitsu et al. 2002). NCEP is given on a $2.5^{\circ}$ resolution $(144 \times 72)$ with 17 vertical levels. NCEP spans 1948 to present, allowing assessing the ability of DePreSys3 to retrospectively predict climate over a longperiod (i.e. over the period 1959-2015). Observed changes in ENSO teleconnection have also been assessed using the twentieth Century reanalysis (Compo et al. 2006) avoiding results to be dependent to NCEP.

\subsection{Southern African rainfall index and Niño3.4 INDEX}

We defined two areas for which we found high skill in predicting austral summer precipitation interannual variability with DePreSys3: SAF covers South Africa $\left[15-30^{\circ} \mathrm{E}\right.$; $35-25^{\circ} \mathrm{S}$ ] and MOZ covers southern Mozambique, Zimbabwe and Northern Botswana $\left[20-35^{\circ} \mathrm{E} ; 15-25^{\circ} \mathrm{S}\right.$ ] (see Fig. 1a). The seasonal cycle of precipitation is not homogenous over the SAF box, where the maximum of precipitation is obtained in austral summer over a large part of southern Africa, while the south-western coastal regions of South Africa experience a maximum of precipitation in austral 
Fig. 1 Anomaly correlation coefficient (ACC) of the summer precipitation in DePreSys3 hindcasts (with respect to GPCC) for a the first summer (i.e. $\operatorname{DJF}(0)$ ) and $\mathbf{b}$ the second summer (i.e. DJF(1)). c SAF and d MOZ precipitation $\left(\mathrm{mm} \mathrm{day}^{-1}\right)$ for observations (GPCC, black line), and DJF(0) (DePreSys3; red line), and DJF(1) (DePreSys3; blue line). Red and blue shadings indicate the ensemble standard deviation. Stippling (on the top panels) indicate that the ACC is significantly different to zero at the $95 \%$ confidence-level according to the Monte Carlo significance test (see text; one sided test). Correlation between observed and simulated precipitation are given on the top right of panels $\mathbf{c}$ and $\mathbf{d}$, stars indicating a correlation significantly different to zero at the $95 \%$ confidence-level
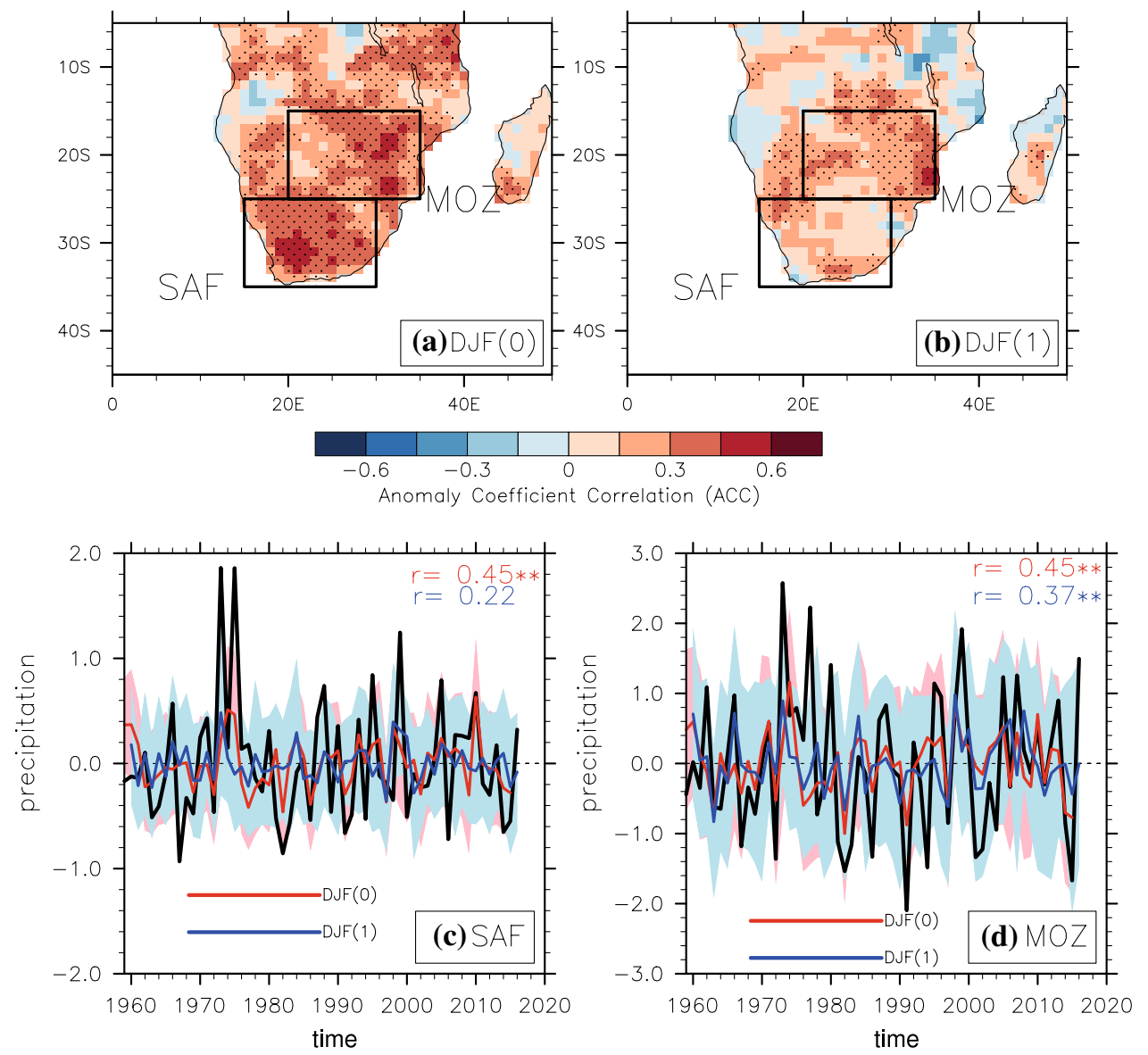

winter (Philippon et al. 2012; Dieppois et al. 2016). Thus, we checked the sensitivity of the results to the exclusion of these grid points for which the seasonal cycle peaks in winter prior to computing the summer precipitation index. Very similar results were found in terms of skill and teleconnections with SAT worldwide (not shown). We performed an empirical orthogonal function (EOFs) to the ACC skill in southern African precipitation, using a 25-year running window, to detect spatially coherent changes in skill. The leading mode highlights that both MOZ and SAF areas are consistent in terms of skill variability (not shown). The skill of DePreSys3 to predict southern African precipitation interannual variability is assessed throughout the paper using GPCC. We also used UDEL (Willmott and Matsuura 2001) and CRU (Harris et al. 2014) to analyse the observed precipitation index but find that results are not sensitive to the choice of the observed dataset (Fig. S1; see the supplementary material).

We used the El Niño3-4 $\left[170-120^{\circ} \mathrm{W} ; 5^{\circ} \mathrm{S}-5^{\circ} \mathrm{N}\right]$ index (hereafter noted EN3.4) to assess the ability of DePreSys3 to simulate ENSO variability. Using EN3.4 enables the comparison of results with other prediction systems (see for instance Gonzalez and Goddard 2016).
We also computed an EOF to estimate ENSO variability and found similar evolution between the first principal component and EN3.4 (with correlation coefficients varying from 0.95 to 0.99 when considering NCEP and DePresys3, and for the first and second DJF lead-time). We also used the El-Niño3 $\left[150-90^{\circ} \mathrm{W} ; 5^{\circ} \mathrm{S}-5^{\circ} \mathrm{N}\right]$ and El-Niño4 index $\left[160 \mathrm{E}-150^{\circ} \mathrm{W} ; 5^{\circ} \mathrm{S}-5^{\circ} \mathrm{N}\right]$, and we did not find any significant difference to results when using EN3.4 (not shown), as also suggested in Ratnam et al. (2014). We thus consider here the EN3.4 index as a good descriptor of ENSO variability, as also seen in Barnston et al. (1999). We do not aim at assessing the impact of the Interdecadal Pacific Oscillation (Zhang et al. 1997; Power et al. 1999), or of the Pacific Decadal Oscillation (Mantua et al. 1997; Minobe 2000; Mantua and Hare 2002; Mills and Walsh 2013), because of the relatively short hindcast durations. The Subtropical Indian Ocean Dipole (SIOD) index allows documenting climate variability over the Indian Ocean, and is defined as the difference between the western $\left[55-65^{\circ} \mathrm{E} ; 37-27^{\circ} \mathrm{S}\right]$ and eastern $\left[90-100^{\circ} \mathrm{E}\right.$; $28-18^{\circ} \mathrm{S}$ ] subtropical Indian Ocean SST anomalies after Behera and Yamagata (2001). 


\subsection{Bias adjustment}

Climate models have biases in simulating the observed climate. Consequently, once initialised from reanalysis, models drift to their preferred (and imperfect) mean climatology. The drift in temperature can reach several degrees Celsius and needs to be removed prior to compare observed and simulated ENSO impacts on southern African precipitation. The most common way to remove the drift is to follow the procedure described in the World Climate Research Program recommendation (ICPO 2011). The drift is then removed, a posteriori and in a linear way, and computed as:

$d r(\tau)=\frac{1}{n m} \sum_{j=1}^{n} \sum_{i=1}^{m} Y_{j}^{i}(\tau)-\frac{1}{n} \sum_{j=1}^{n} X_{j}(\tau)$

where $Y$ and $X$ are given for a member $i$ and a start date $j$ for respectively DePreSys 3 and the corresponding observations/ reanalysis (i.e. NCEP for atmospheric variables and GPCC for precipitation), spanning $n$ start dates and $m$ members. Thus, the drift, $d r$, is only lead-time $(\tau)$ dependent, and is assumed to be start date independent. Here, we assume that the ICPO method is reliable to remove the drift for a large range of variables and over several regions.

\subsection{Evaluation of the model skill}

We evaluate the ability of DePreSys 3 to predict climate by computing the Anomaly Correlation Coefficient (ACC) between DePreSys3 hindcasts and observations/reanalysis for a given lead-time. The significance of ACC values is assessed by performing a Monte Carlo procedure through resampling (5000 permutations). Synthetic time-series are randomly resampled using blocks of 5-year periods and filled until the size of the original time-series is reached, to preserve the multi-annual variability. Correlation between DePreSys3 and observed/reanalysed time-series are then computed for each permutation. The obtained correlations follow a Gaussian distribution, and are considered as significant at $\mathrm{p} \leq 0.05$ (i.e. $95 \%$ confidence level) when observed correlation values are greater than the 95 th percentile of the permutation distribution (i.e. a one-sided test). The same procedure is used to evaluate the significance of the regressions, but using a two-sided test (regression values are then considered significant when regression coefficients are lower than the 2.5 th percentile, or greater than the 97.5th percentile, of the permutation distribution).

\section{Skill in predicting southern African precipitation}

\subsection{Overall skill in predicting southern African precipitation}

The ACC for DePreSys3 to predict interannual southern African precipitation variability in austral summer (DJF) is shown in Fig. 1. A linear trend was removed for each gridpoint, to compute the ACC, relative to the long-term trend. For the first summer [hereafter noted DJF(0)], ACC values are significant and up to 0.45 over both South Africa and West of Mozambique, over the period 1959-2015 (Fig. 1a). Skill in predicting precipitation decreases for the 2nd summer [hereafter noted DJF(1)], 13-16 months ahead; Fig. 1b. DePreSys3 is not able to predict precipitation over South Africa for the 2nd summer, but prediction skill remains positive and significant between $15^{\circ} \mathrm{S}$ and $25^{\circ} \mathrm{S}$ (Fig. 1a, b). Prediction skill has also been assessed using CRU and UDEL data sets, and very similar results were found (Fig. S2).

As expected, simulated ensemble-mean precipitation anomalies have a smaller variability to the observed (Fig. 1c, d). However, resampling the dataset (i.e. by computing 10,000 synthetic 57 years long time series, taking one randomly selected member by start dates) shows that DePreSys 3 underestimates SAF precipitation variance and overestimates $\mathrm{MOZ}$ precipitation variance for both $\mathrm{DJF}(0)$ and DJF(1) (Fig. S3).

The large observed peaks of the extreme years tend to be reproduced (e.g. precipitation anomaly of a same sign; Fig. 1c, d). Generally, anomalously wet years are associated with La-Niña (e.g. 1973-1974, 1975-1976, 1988-1989, 1999-2000, 2007-2008 and 2010-2011), while exceptional dry years are associated with El-Niño (e.g. 1972-1973, 1982-1983, 1991-1992, 2015-2016).

\subsection{Sources of skill in predicting southern African precipitation}

Skill in predicting southern African precipitation is primarily related to ENSO (Landman et al. 2001; Reason et al. 2006; Landman and Beraki 2012; Beraki et al. 2013). Thus we explore the ENSO teleconnection with southern African precipitation, as simulated and predicted by DePreSys3. We have chosen to focus mainly on ENSO teleconnection for $\operatorname{DJF}(0)$ in the main text, which is the most skilful over both SAF and MOZ areas. Results obtained for $\operatorname{DJF}(1)$ are also relevant, as they provide prediction up to 16 month ahead and are discussed throughout the text and presented in the supplementary materials. However, 
time-evolution of skill in predicting precipitation and temperature for $\operatorname{DJF}(0)$ and $\operatorname{DJF}(1)$ are presented side-by-side to allow comparing both lead-times and document better their dependence on the forecast evaluation period.

Figure 2 shows the SST anomalies that are related to southern African precipitation variability by regressing the standardized linearly detrended index of SAF and MOZ precipitation with linearly detrended SAT globally at each grid box. The largest SAT anomalies are found over the equatorial Pacific Ocean in both observations and DePreSys3 (Fig. 2). Therefore, Fig. 2 suggests that DePreSys3 is able to simulate the observed link between ENSO variability and southern African precipitation. High correlations are also found between the EN3.4 index and SAF precipitation $(-0.55$ and -0.67 in observation and DePreSys3, respectively) and MOZ precipitation ( -0.60 and -0.63 in observation and DePreSys3, respectively), with DePreSys3 overestimating correlations between EN3.4 index and southern African precipitation.

In Fig. 3, we explore the relationship between ENSO and southern African climate in observations and DePreSys3. Specifically, precipitation, $250 \mathrm{hPa}$ velocity potential and divergence wind, $850 \mathrm{hPa}$ geopotential height and moisture flux are regressed onto the EN3.4. In both observations and DePreSys3 regressions show negative precipitation anomalies south of $15^{\circ} \mathrm{S}$ (Fig. 3a, b). The change in precipitation in both observations and model is associated with large-scale changes occurring in the upper troposphere, with anomalously strong divergence over the eastern Pacific Ocean, while anomalously strong convergence occurs over the warm pool, i.e. a modulation of the Walker circulation (Fig. 3c, d). As a consequence, anomalous subsidence is found over the western Pacific Ocean, eastern Indian Ocean and southern Africa. In addition, the large-scale changes are associated with a northward shift of both South Atlantic and South Indian Ocean anticyclonic circulations (Cook et al. 2004; Vigaud et al. 2009; Philippon et al. 2012; Ratnam et al. 2014; Dieppois et al. 2015), as evidenced by the decrease in geopotential height at $850 \mathrm{hPa}(\mathrm{zg} 850)$ south of $35^{\circ} \mathrm{S}$, and an increase north of $35^{\circ} \mathrm{S}$ (Fig. 3e, f). The shift in the location of the subtropical highs leads to a change in the low-level atmospheric circulation and reduced moisture flux inland south of $20^{\circ} \mathrm{S}$ (Fig. 3e, f), consistent with decreased SAF and MOZ precipitation (Rouault et al. 2003; Reason and Jagadheesha 2005; Lyon and Mason 2007; Ratnam et al. 2014; Vizy et al. 2015; Dieppois et al. 2015). Additionally, anomalous subsidence over southern Africa favours stable conditions and the decrease in precipitation (Fig. 3c, d). Therefore, DePreSys3 is able to simulate the relationship between southern African precipitation and

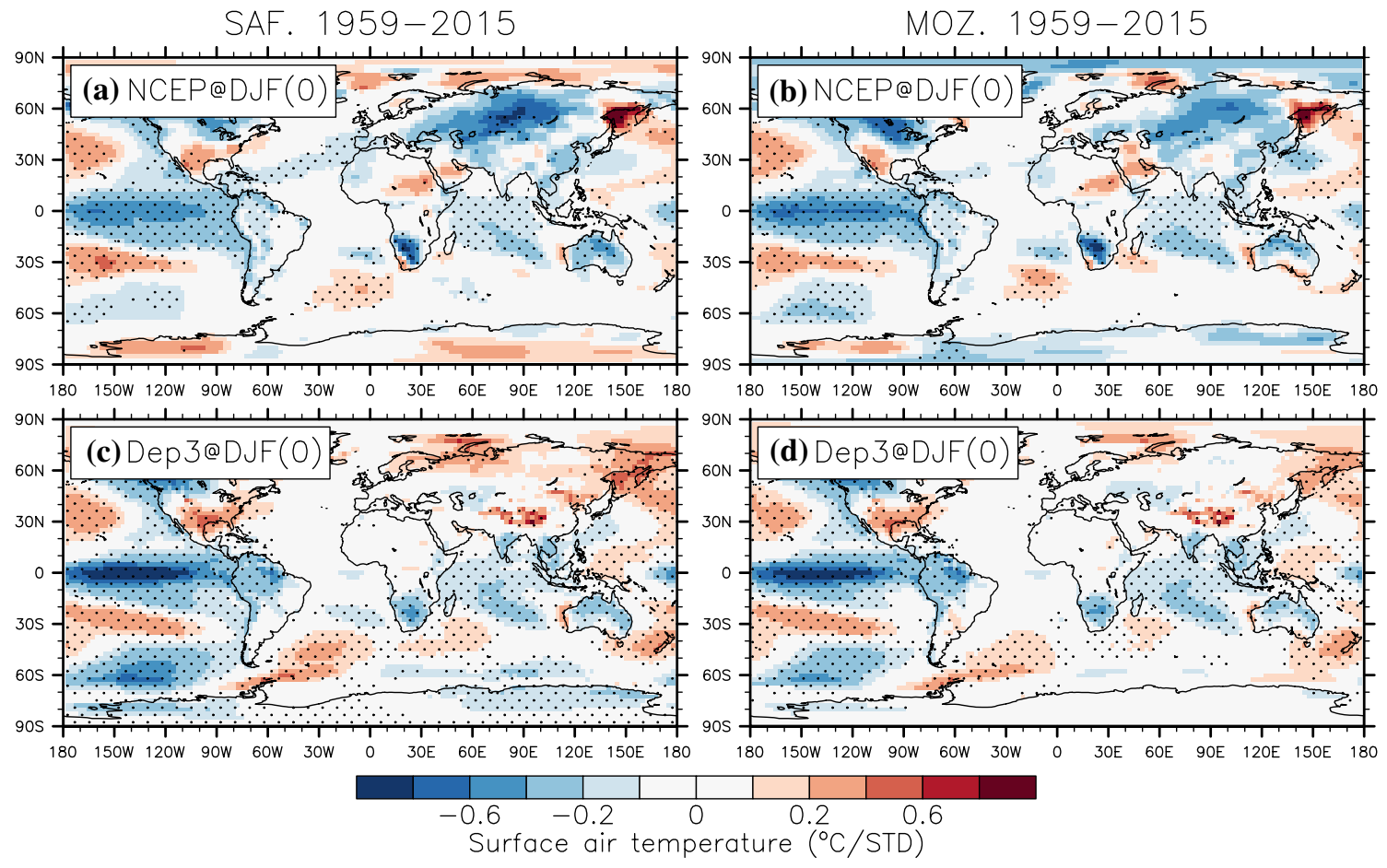

Fig. 2 Surface air temperature $\left({ }^{\circ} \mathrm{C} / \mathrm{STD}\right)$ regressed onto the precipitation index for (top panels) observations (NCEP and GPCC) and (bottom panels) DePreSys3 for the first summer lead time (i.e. DJF(0)). Left panels: regressions to the SAF precipitation index. Right panels: regressions to the MOZ precipitation index. Regressions are performed over the period 1959-2015. Stippling indicates that the regression is significantly different to zero at the $95 \%$ confidencelevel according to the Monte Carlo procedure (see text; two-sided test). For DePreSys3 results were computed using the ensemble mean 

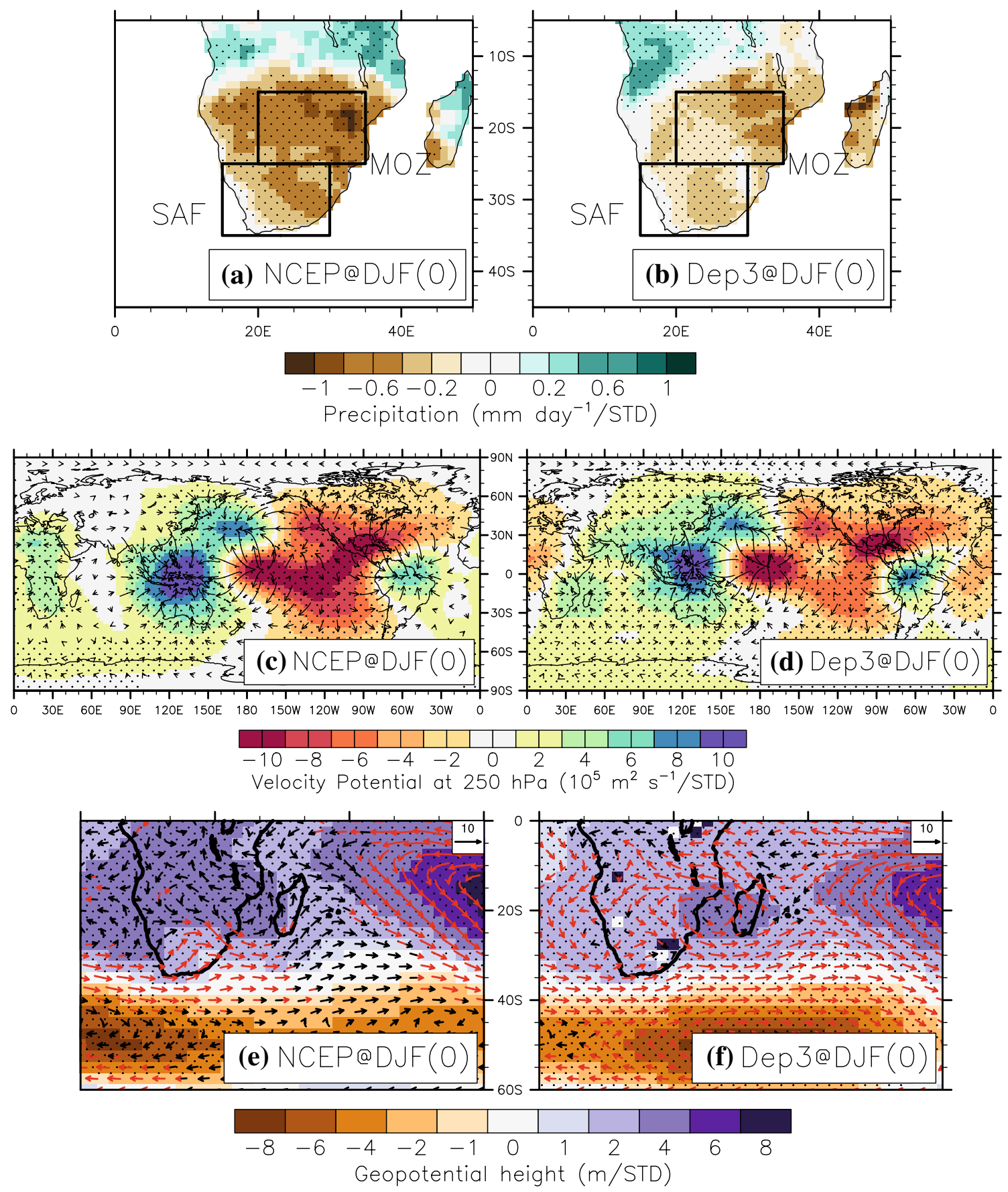

Fig. 3 (top panels) Precipitation (mm day ${ }^{-1} / \mathrm{STD}$ ), (middle panels) $250 \mathrm{hPa}$ Velocity Potential $\left(10^{5} \mathrm{~m}^{2} \mathrm{~s}^{-1} / \mathrm{STD}\right.$; shading) and divergent winds ( $\mathrm{m} \mathrm{s}^{-1} / \mathrm{STD}$; vectors) and (bottom panels) $850 \mathrm{hPa}$ Geopotential Height (m/STD; shading) and moisture flux $\left(\mathrm{g}, \mathrm{Kg}^{-1} \mathrm{~m} \mathrm{~s}^{-1} / \mathrm{STD}\right.$; vectors) regressed onto the EN3.4 index for the first summer leadtime (DJF(0)) in (left column) NCEP and GPCC and (right column)

ENSO variability (note very similar results are obtained for the second DJF (i.e. DJF(1); Fig S5).

Precipitation anomalies over southern Africa are not only related to the equatorial Pacific Ocean. Observed and simulated precipitation anomalies are also associated with
DePreSys3. Regressions are performed over the period 1959-2015. Stippling and red arrows indicate that the regression is significantly different to zero at the $95 \%$ confidence-level according to the Monte Carlo procedure (see text; two sided test). For DePreSys3 results were computed using the ensemble mean

the South Indian Ocean Dipole (SIOD; Fig. 2), as proposed in earlier studies (Nicholson and Kim 1997; Reason and Mulenga 1999; Reason and Rouault 2002; Washington and Preston 2006; Morioka et al. 2015; Hoell et al. 2017a, b; Hoell and Cheng 2018). The SIOD refers to a warming south 
of Madagascar and a cooling north and east of Madagascar. A relation between both the MOZ and SAF precipitation is obtained with the SIOD in DePreSys3 (Fig. 2c, d). Moreover, wet conditions across southern Africa are also associated with anomalously warm temperature over the South Atlantic Ocean in both observations and DePreSys3 (Fig. 2a-d), as shown in Vigaud et al. (2009). Although weaker, the relationship between ENSO, SIOD, and the South Atlantic Ocean with southern African precipitation are also simulated by DePreSys3 for the second DJF lead time (Fig. S6).

\subsection{Skill in predicting EN3.4 and SIOD index}

There is high skill in predicting temperature for $\operatorname{DJF}(0)$ over the tropics in DePreSys3 with significant correlations over the Pacific Ocean (up to 0.9), the Atlantic and South Indian Ocean (Fig. 4a, b). ACC values decrease for the second summer lead-time, but remain significant over the Pacific Ocean, over the southern Indian Ocean and become very weak over the southern Atlantic Ocean (Fig. 4a, b). DePreSys3 thus exhibits a very high skill in predicting EN3.4 in $\operatorname{DJF}(0)$ and a significant and high skill in DJF (1), regardless the period considered (Fig. 4c). The skill in predicting precipitation over southern Africa is therefore consistent with the ability of DePreSys3 to predict ENSO. The SIOD index is significantly predicted at the $\mathrm{DJF}(0)$ lead-time but $\mathrm{ACC}$ values drop sharply for the second DJF lead time (Fig. 4d).

\subsection{Sensitivity of the skill to forecast evaluation period}

Skill in predicting southern African precipitation has been associated with the remote impact of SSTs over land (Landman et al. 2001; Reason et al. 2006; Landman and Beraki 2012). However, teleconnections are not stationary (Richard et al. 2000, 2001), and skill in predicting southern African precipitation may thus have changed with time. In order to assess whether skill changes in different periods, we computed the ACC skill for predictions of SAF and MOZ precipitation using a moving window of 25 years (Fig. 5a, b). Results indicate that the skill in predicting SAF precipitation for the first summer is almost continuously statistically significant, varying around 0.5 . However, for the second summer, the skill drops sharply in the mid-1980s, and is not significant thereafter (at the 95\% confidence level; Fig. 5a). For MOZ, skill in predicting precipitation increases after the 1990s for the first summer, while the skill is relatively constant for the second summer lead-time (Fig. 5b). These changes in skill are significant over large areas of the selected boxes (Fig. S7).

Due to their strong impacts, large ENSO events can strongly modulate the ACC skill values. We assess the sensitivity of skill to one particular ENSO event by computing ACC from time series for which one ENSO event has been discarded. This operation is repeated as many times as need to test the impact of each ENSO events on skill in predicting southern African precipitation (Fig. S8). Discarding the events of 1973, 1975 and 1999 leads to changes in skill over both SAF and MOZ (Figs. 5c, d and S8). Over the period 1959-2015, ACC exhibits then a value of $0.37(0.15)$ and of $0.44(0.29)$ for respectively SAF and MOZ precipitation and for $\operatorname{DJF}(0)$ (DJF(1)). Interestingly (1) these years are La-Niña events and (2) the impact of the 1973-1974 and 1999-2000 events on precipitation are better predicted 1 year ahead than for $\operatorname{DJF}(0)$ (Fig. S4). The 1973-1974 and 1999-2000 events were also preceded by an El-Niño event, which suggests a successful prediction 1 year ahead due to the ocean dynamics (e.g. an El-Niño event followed by a La-Niña event, the asymmetry in ENSO cycle (Kessler 2002).

Removing these three events from the time series yields a different picture that is now only representative of the longterm change in the skill in predicting precipitation. Skill in predicting SAF is stronger over the period 1990-2015 than over the period 1959-1985 for the first DJF lead time (Fig. 5c, d). Skill in predicting SAF precipitation for DJF(1) decreases with time, but is never significant at the $95 \%$ confidence level, highlighting the high impact of large ENSO events on ACC values, as shown in Landman et al. (2001), Reason et al. (2006), Landman and Beraki (2012). The broad picture stays relatively similar for $\mathrm{MOZ}$ precipitation with increasing ACC values for $\mathrm{DJF}(0)$ and pretty stable $\mathrm{ACC}$ values for $\mathrm{DJF}(1)$. Unlike precipitation hindcasts, the prediction skill for the EN3.4 index does not change with time (see also Dunstone et al. 2016) (Fig. 4c, d). As for EN3.4 we do not identify any strong changes in the ability of DePreSys 3 to predict SIOD index with time. The same analysis is reproduced after discarding the ENSO events of 73-74, 75-76 and 99-00 without yielding to significant changes (Fig. 4e, f).

The main question that arises from the results we obtained so far is to understand the reason why the prediction skill over southern Africa varies in time, as it has clear and strong implications for decision makers. To do so, we explore the source of skill in predicting SAF and MOZ precipitation in the next subsection. Since we aim at documenting the long-term change in skill in predicting precipitation the events of 1973-1974, 1975-1976 and 1999-2000 are discarded in the next analysis and the focus is made on the $\operatorname{DJF}(0)$. 

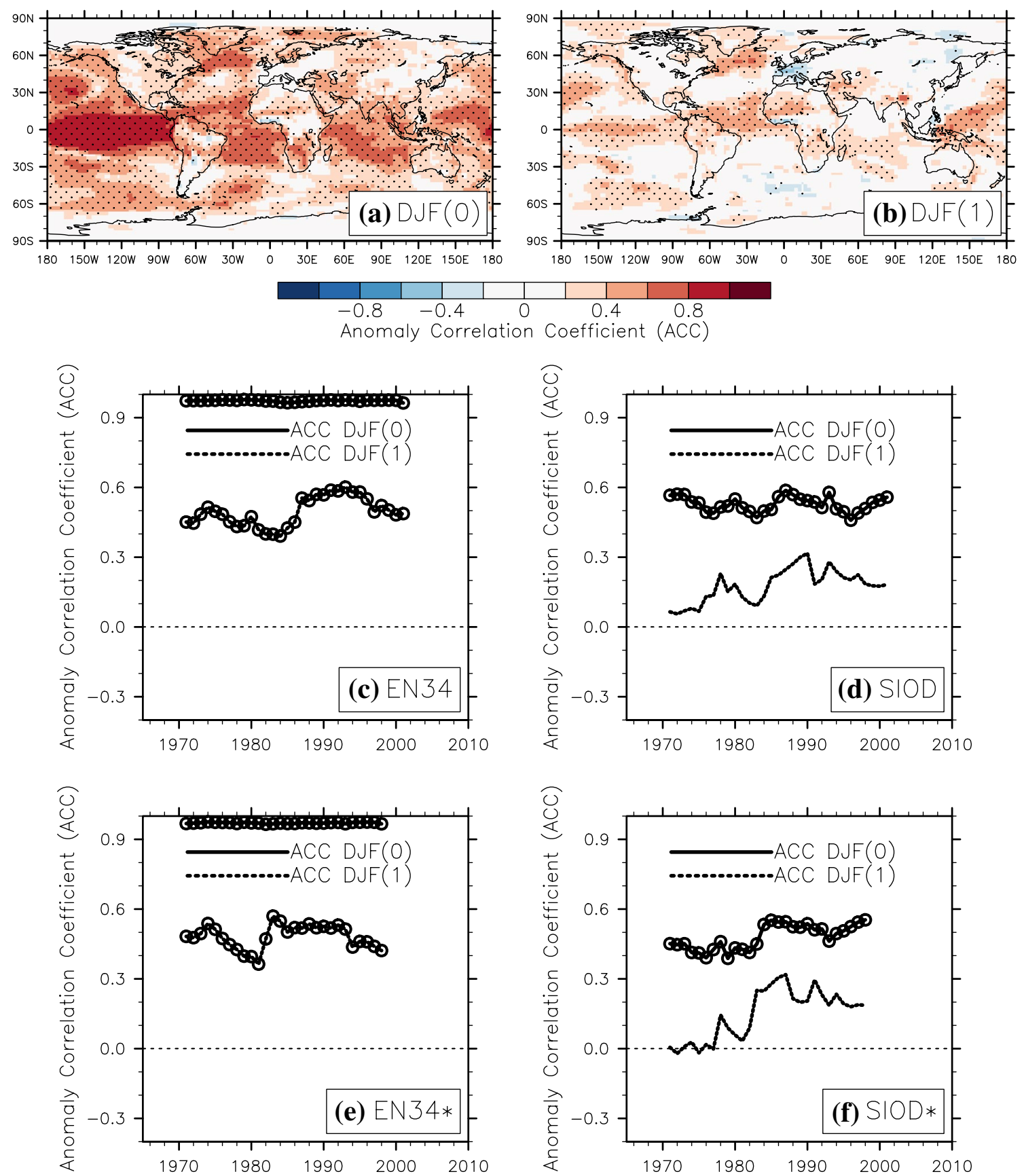

Fig. 4 Anomaly Correlation Coefficient (ACC) of the EN3.4 hindcasts in DePreSys3 hindcasts (with respect to NCEP) for a the first summer (i.e. $\operatorname{DJF}(0)$ ) and $\mathbf{b}$ the second summer (i.e. DJF(1)). Stippling (on a, b) indicate that the ACC is significantly different to zero at the $95 \%$ confidence-level according to the Monte Carlo significance test (see text; one sided test). ACC skill in DePreSys3 com-

\section{Processes leading to decadal timescale changes in ENSO teleconnection}

\subsection{ENSO pattern}

In the NCEP reanalysis data, El-Niño is associated with

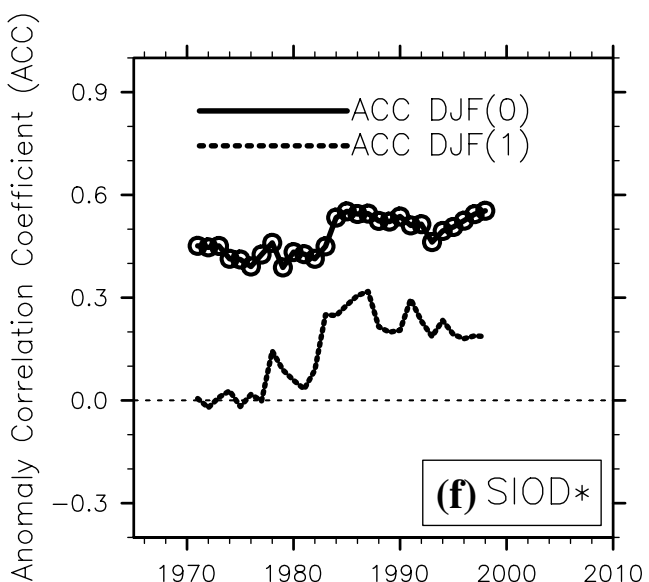

puted for a moving window of 25 years (plotted at the central year of the moving window) for $\mathbf{c}$ EN3.4 index and d SIOD index. e, f: as in c and $\mathbf{d}$ but after having discarded the ENSO events of 1973-1974, 1975-1976 and 1999-2000. Black circles indicate that the ACC is significantly different to zero at the $95 \%$ confidence-level according to the Monte Carlo significance test (see text; one sided test)

an increased SAT over the equatorial Pacific Ocean, with a horseshoe pattern of opposite sign on the western Pacific Ocean and over the subtropics (Fig. 6a, c). El-Niño is also associated with an increased SAT over the tropical Indian Ocean (Klein et al. 1999; Zhong et al. 2005) and over southern Africa. Over the period 1990-2015, ENSO is associated 
Fig. 5 ACC skill in DePreSys 3 computed for a moving window of 25 years (plotted at the central year of the moving window) for a SAF precipitation and $\mathbf{b} \mathrm{MOZ}$ precipitation (see the boxes on the Fig. 1a, b). c, $\mathbf{d}$ Same as in $\mathbf{a}, \mathbf{b}$ but after having discarded the DJF of 1973-1974, 1975-1976 and 1999-2000 (i.e. SAF* and MOZ*). Black circles indicate that the ACC is significantly different to zero at the $95 \%$ confidence-level according to the Monte Carlo significance test (see text; one sided test)
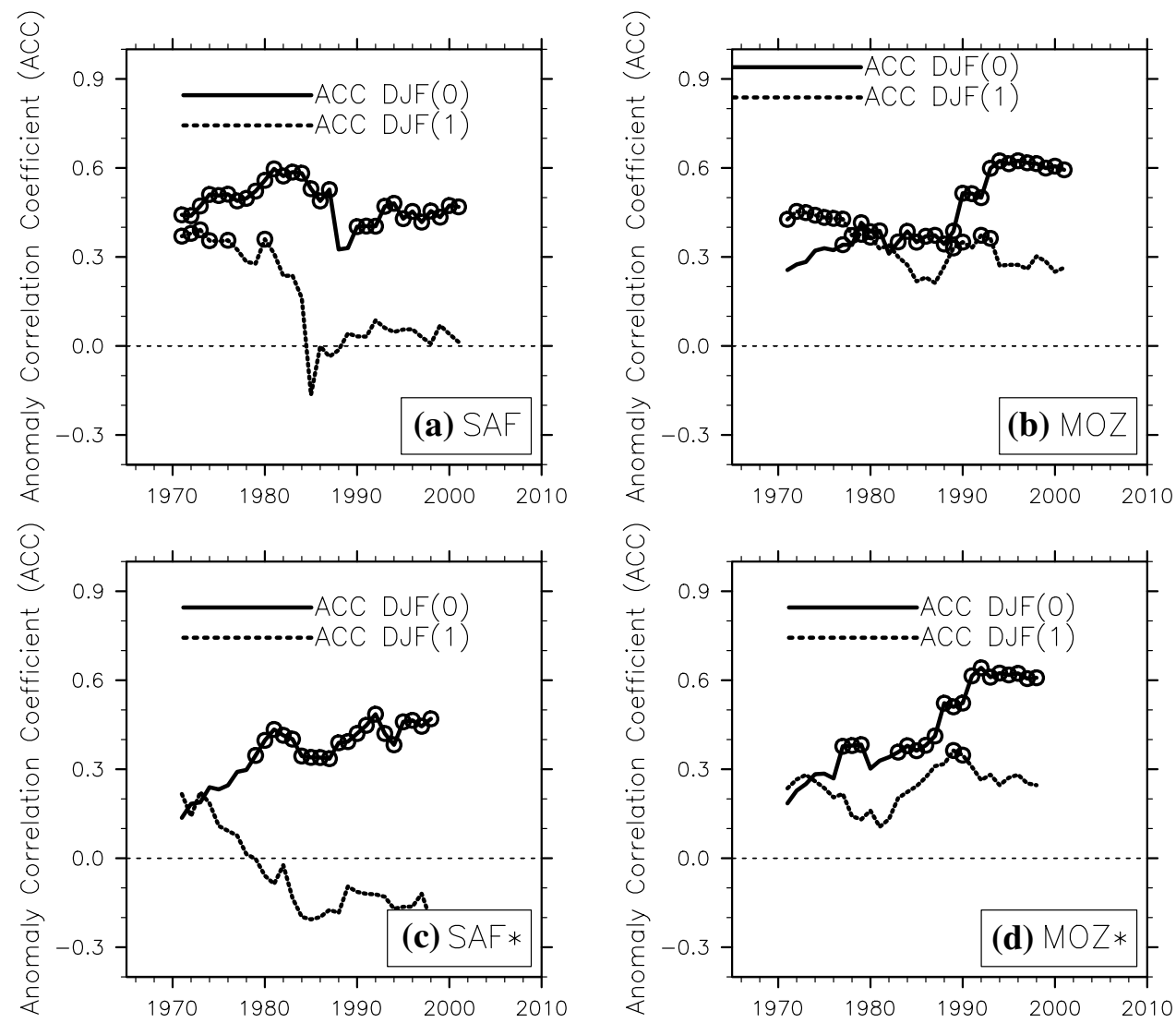

with a higher warming between $180^{\circ} \mathrm{W}$ and $150^{\circ} \mathrm{W}$ over the central Pacific Ocean compared to 1959-1985 (Fig. 6e). In comparison, DePreSys 3 correctly simulates an increase in the ENSO-related SAT over the equatorial Pacific Ocean, and a decrease over the subtropics and over the southeast Indian Ocean (Fig. 6b, d). DePreSys3 is able to reproduce the apparent change of the ENSO impacts after 1990 (Fig. 6f), with the pattern difference of SAT regression associated with ENSO positive phase between two periods, which are reminiscent of positive Interdecadal Pacific Oscillation (IPO) phase. However, the changes seen in NCEP (and in the twentieth century reanalysis; not shown) are not reproduced for the second austral summer lead time in DePreSys3 (Fig. S9).

\subsection{The non-stationarity in ENSO impacts over southern Africa}

El-Niño events are associated with dry conditions over southern Africa in both the 1959-1985 and 1990-2015 periods in observations and DePreSys3 (Fig. 7a, d). Note that the relation between EN3.4 index and SAF precipitation are stronger (and significant at the $95 \%$ confidence level), when adding the events of 1973-1974, 1975-1976 and 1999-2000 (not shown). DePreSys3 underestimates the impact of ENSO (Fig. 7b-d; as also assessed through resampling DePreSys3 dataset; Fig S10), as most CMIP5 models (Dieppois et al. 2015). Comparing the two sub-periods highlights a non-negligible interdecadal change in the observed ENSO-precipitation relationship. The link between ENSO and MOZ rainfall is weaker in the period 1959-1985 than in the post-1990 period (Fig. 7e). Computing correlations instead of regressions confirms that MOZ precipitation variability is more linked to ENSO variability after 1990 and that simulated southern African precipitation variability is strongly related to ENSO in the whole period (Fig. S11). The part of the MOZ precipitation variance explained by ENSO variability is therefore closer between DePreSys3 and observation after 1990 than before 1990 (Fig. S3). We hypothesise that this change in the ENSO-MOZ precipitation teleconnection might lead to an increase in skill in retrospectively predicting MOZ precipitation. Before 1990, DePreSys3 is not able to accurately reproduce the link between EN3.4 index and MOZ precipitation, and DePreSys 3 is not able to simulate the change in the ENSO-MOZ precipitation relation (Fig. 7f), yielding weaker ACC values.

\subsection{Change in the atmospheric circulation response to ENSO and its impact on southern African precipitation}

El-Niño is associated, over both 1959-1985 and 1990-2015 periods, with significant positive anomalies 

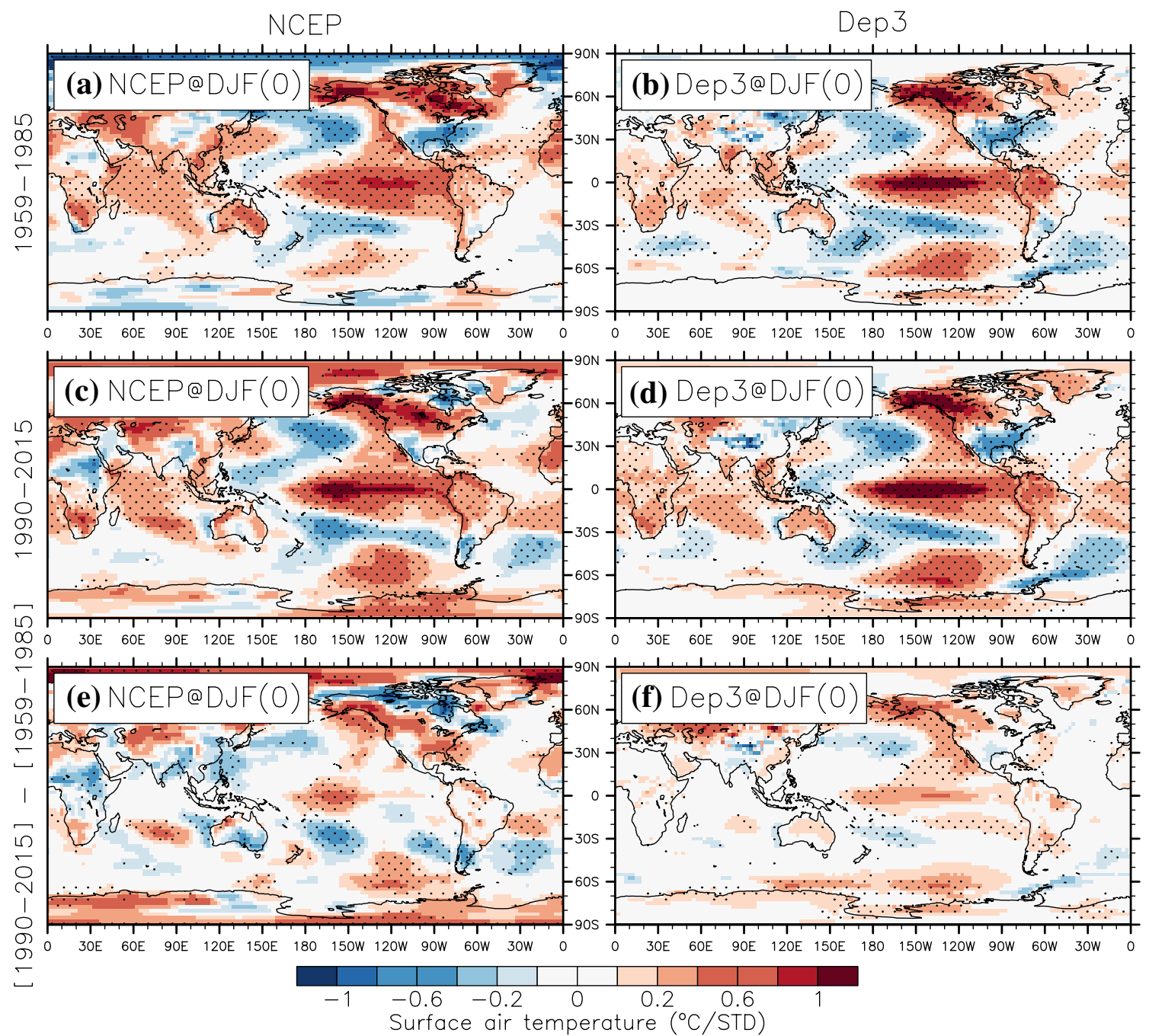

Fig. 6 Surface air temperature $\left({ }^{\circ} \mathrm{C} / \mathrm{STD}\right)$ regressed onto the EN3.4 index for NCEP (left column) and DePreSys3 (right column) for the first summer lead-time. Regressions are performed over the (top panels) period 1959-1985 and the (middle panels) period 1990-2015. Difference between the top and middle panels is given within the bottom panels (middle minus top). a-d Stippling indicates that the regression is significantly different to zero at the $95 \%$ confidencelevel according to the Monte Carlo procedure (see text; two sided

in observed upper-level velocity potential (VP), which extend from southern Africa to the western Pacific Ocean, indicating an anomalous upper level convergence and descent (Fig. 8a). Over the 1990-2015 period, the observed VP anomalies are similar to those observed over the 1959-1985; however, negative VP anomalies, which are associated with an increase in deep convection North and East of Madagascar (Fig. S12) emerge over the Indian Ocean (Fig. 8c), highlighting that VP anomalies are sensitive to changes in temperature over the Indian Ocean (they also for instance vary strongly from an El-Niño event to another; Fig. S13). The observed VP anomalies associated test) for the regression performed over the 1959-1985 and 19902015 periods and $\mathbf{e}, \mathbf{f}$ that the difference between the regressions performed over the 1959-1985 and 1990-2015 periods are statistically different to zero (at the $90 \%$ confidence-level according to the Monte Carlo procedure, with one sided test). Events of 1973-1974, 19751976 and 1999-2000 have been discarded from the time series. For DePreSys3 results were computed using the ensemble mean

with ENSO are also stronger over the central Pacific Ocean in the 1990-2015 period than in the 1959-1985 period (Fig. 8e), consistent with a warmer central Pacific Ocean and a colder maritime continent (Fig. 6e).

Similarly, DePreSys 3 simulates a weakening of the Walker-cell under El-Niño conditions resulting in upperlevel convergence and less air ascent over the equatorial Indian Ocean and southern Africa (Fig. 8b, d), albeit with a weaker intensity than in observations. In contrast, the ENSO-VP is not sensitive to the time periods in DePreSys3 (Fig. 8f) and the divergence anomalies are not present over the Indian Ocean between 1990 and 2015 (Fig. 8c, d). 
Fig. 7 Precipitation $\left(\mathrm{mm} \mathrm{day}{ }^{-1 /}\right.$ STD) regressed onto the EN3.4 index for (left column) GPCC and NCEP (right column) DePreSys 3 for the first summer lead-time. Regressions are performed over the (top panels) period 1959-1985 and the (middle panels) period 1990-2015. Difference between the top and middle panels is given within the bottom panels. a-d Stippling indicates that the regression is significantly different to zero at the $95 \%$ confidencelevel according to the Monte Carlo procedure (see text; two sided test) for the regression performed over the 1959-1985 and 1990-2015 periods and $\mathbf{e}$, f that the difference between the regressions performed over the 1959-1985 and 1990-2015 periods are statistically different to zero (at the $90 \%$ confidencelevel according to the Monte Carlo procedure, with one sided test). Events of 1973-1974, 1975-1976 and 1999-2000 have been discarded from the time series. For DePreSys3 results were computed using the ensemble mean

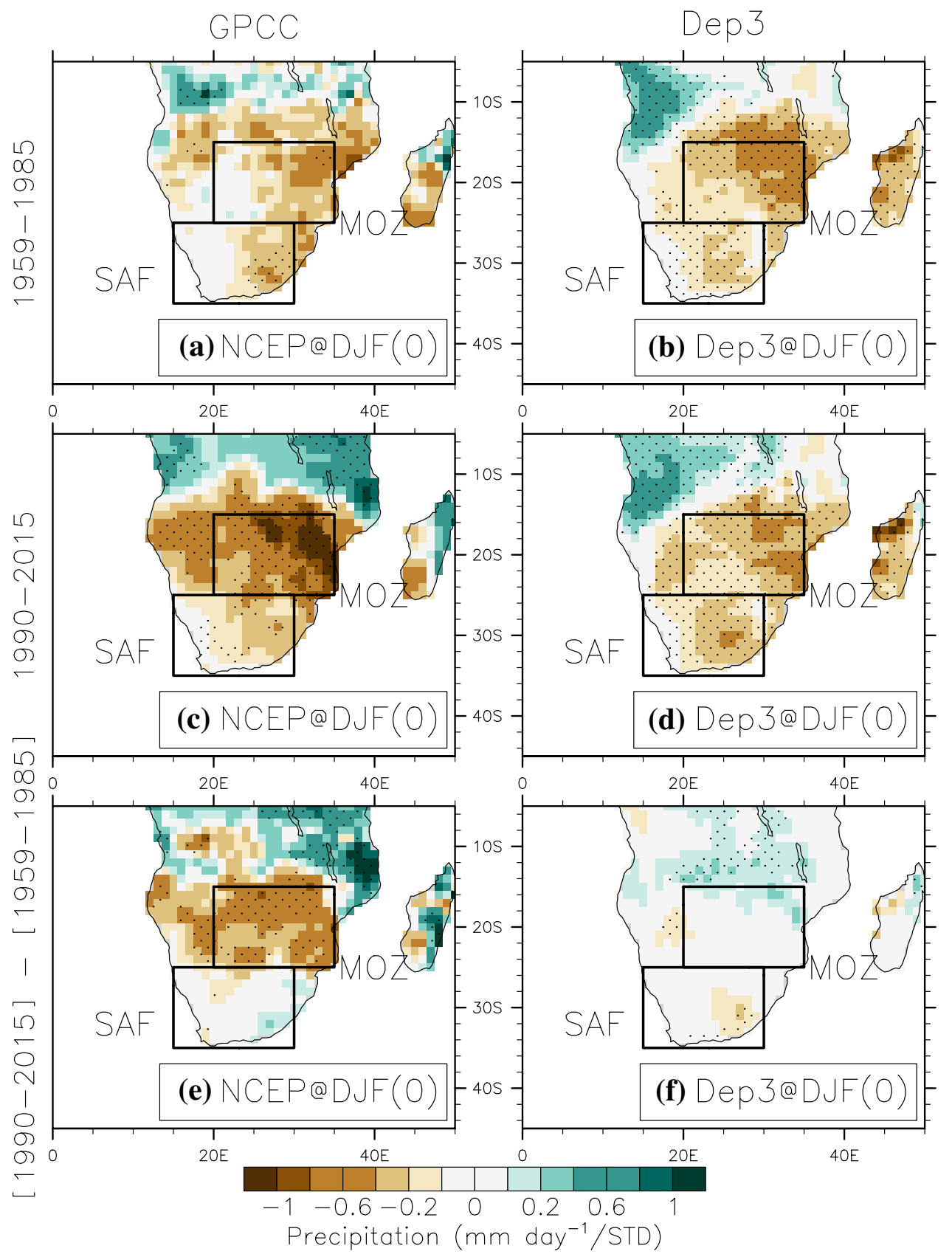

The observed precipitation anomalies associated with El Nino events in the 1959-1985 time period are consistent with the northward shift of the subtropical high pressure system (see Fig. 9a for the climatology), which acts to weaken moisture transport from the ocean over most of southern Africa, and to carry more moisture north of $10^{\circ} \mathrm{S}$ (Fig. 9b). After 1990, regression pattern shows a positive anomaly in $\mathrm{zg} 850$ over the western region of southern Africa, and is associated with an anomalously strong anticyclonic circulation. This weakening of the Angola Low leads to an increase in the moisture flux north of $15^{\circ} \mathrm{S}$, and a decrease moisture flux south of $15^{\circ} \mathrm{S}$, which is consistent with the changes in the precipitation relationship around $15^{\circ} \mathrm{S}$ (Fig. $7 \mathrm{~b}$ ). The difference of regression patterns against the EN3.4 index between the two sub-periods denotes an increase in zg850 over and south of southern Africa while zg850 decreases eastward of Madagascar (Fig. 9f), with an increase in northward moisture flux, and moisture convergence (Fig S14), over MOZ. A weakened Angola Low, and an export of moisture northward, are also obtained at $500 \mathrm{hPa}$ (Fig. S14 and Fig. S15).

In DePreSys3 we do not see similar changes in ENSO's effect on the regional circulation as measured by $\mathrm{zg} 850$ (Fig. 9). In both 1959-1985 and 1990-2015 periods, the 

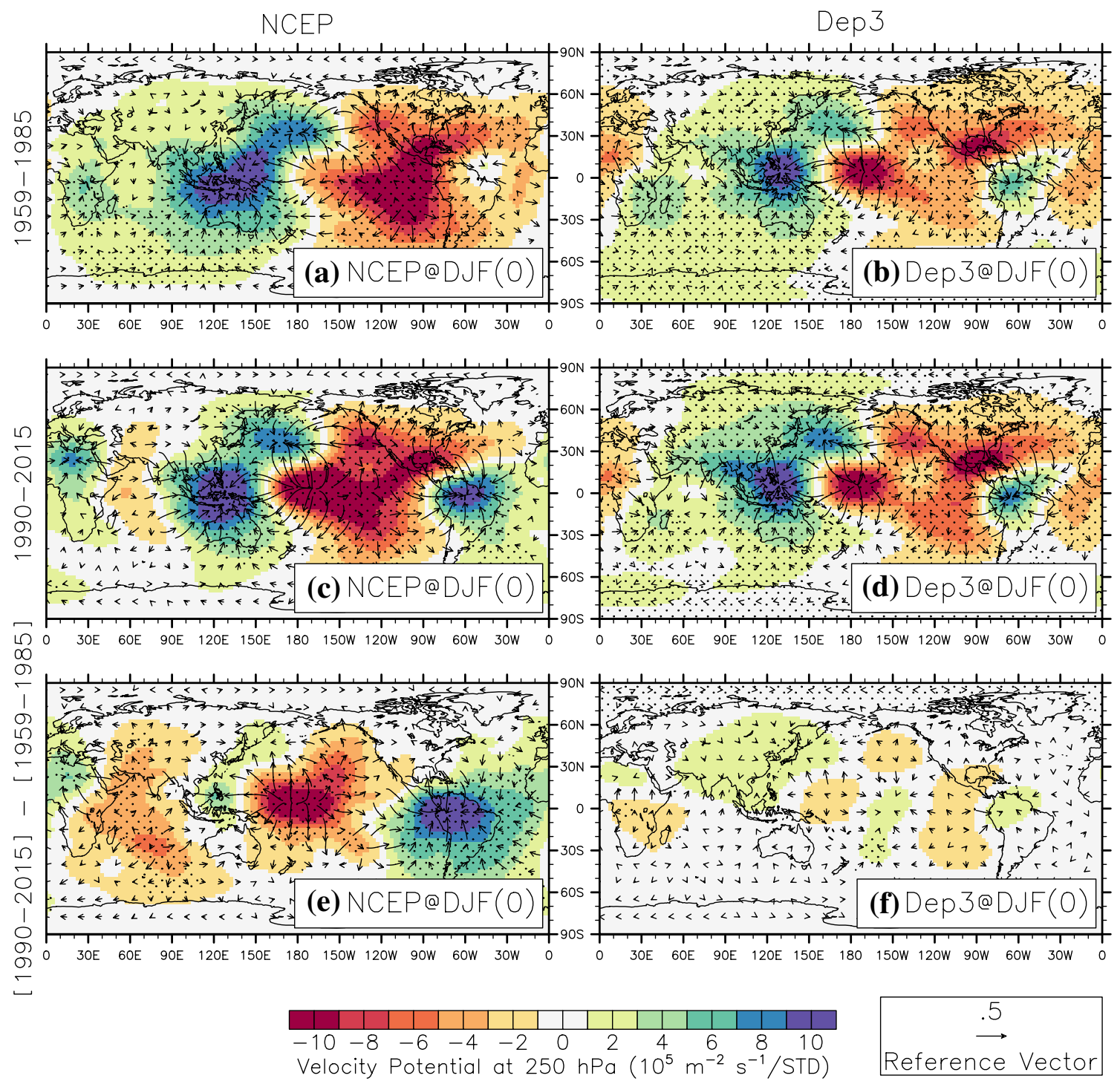

Fig. $8250 \mathrm{hPa}$ Velocity Potential $\left(10^{5} \mathrm{~m}^{-2} \mathrm{~s}^{-1} / \mathrm{STD}\right.$; shading $)$ and divergent winds ( $\mathrm{m} \mathrm{s}^{-1} / \mathrm{STD}$; vectors) regressed onto the EN3.4 index for (left column) NCEP and for (right column) DePreSys3 for the first summer lead-time. Regressions are performed over the (top panels) period 1959-1985 and the (middle panels) period 1990-2015. Difference between the top and middle panels is given within the bottom panels. a-d Stippling indicates that the regression is significantly different to zero at the $95 \%$ confidence-level according to the
Monte Carlo procedure (see text; two sided test) for the regression performed over the 1959-1985 and 1990-2015 periods and e, f that the difference between the regressions performed over the 1959-1985 and 1990-2015 periods are statistically different to zero (at the $90 \%$ confidence-level according to the Monte Carlo procedure, with one sided test). Events of 1973-1974, 1975-1976 and 1999-2000 have been discarded from the time series. For DePreSys 3 results were computed using the ensemble mean northward shift of the anticyclonic circulation associated with ENSO variability extends from South Africa across the Indian Ocean (Fig. 9c, e). These anomalies lead to an anomalously anticyclonic circulation between Mozambique and Madagascar and allow moisture fluxes and deepconvection to weaken over land south of $20^{\circ} \mathrm{S}$ (Figs. 9c, e, S15). In contrast, moisture fluxes strengthen to north of $25^{\circ} \mathrm{S}$, in association with increased precipitation (Fig. 9c, e). Thus, DePreSys3 is able to simulate the impact of
ENSO on the regional circulation over southern African in DePreSys3, especially for the period 1959-1985.

Observed changes in ENSO teleconnection have also been assessed using the NOAA-twentieth Century reanalysis (Compo et al. 2006) to ensure that the results do not only rely on the NCEP reanalysis data. The twentieth Century reanalysis also revealed changes similar to those identified in NCEP (i.e. ENSO teleconnection is associated with a warmer central Pacific and South Indian Ocean, 
Fig. 9 a Climatology (longterm mean computed over the 1959-2015 period in NCEP) of $850 \mathrm{hPa}$ Geopotential Height ( $\mathrm{m}$; shading) and moisture flux ( $\mathrm{g}, \mathrm{Kg}^{-1} \mathrm{~m} \mathrm{~s}^{-1}$; vectors). $850 \mathrm{hPa}$ Geopotential Height (m/STD; shading) and moisture flux $\left(\mathrm{g}, \mathrm{Kg}^{-1} \mathrm{~m} \mathrm{~s}^{-1} / \mathrm{STD}\right.$; vectors) regressed onto the EN3.4 index for (left column) NCEP and (right column) DePreSys3 for the first summer lead-time. Regressions are performed over the $\mathbf{b}$ and $\mathbf{c}$ period 1959-1985 and the (d and e) period 19902015. Difference between the top and middle panels is given within the bottom panels. b-e Stippling (red arrows) indicates that the regression is significantly different to zero at the 95\% confidence-level according to the Monte Carlo procedure (see text; two sided test) for the regression performed over the 1959-1985 and 1990-2015 periods and $\mathbf{f}-\mathbf{g}$ that the difference between the regressions performed over the 1959-1985 and 1990-2015 periods are statistically different to zero (at the 90\% confidence-level according to the Monte Carlo procedure, with one sided test). Events of 1973-1974, 1975-1976 and 1999-2000 have been discarded from the time series. For DePreSys3 results were computed using the ensemble mean
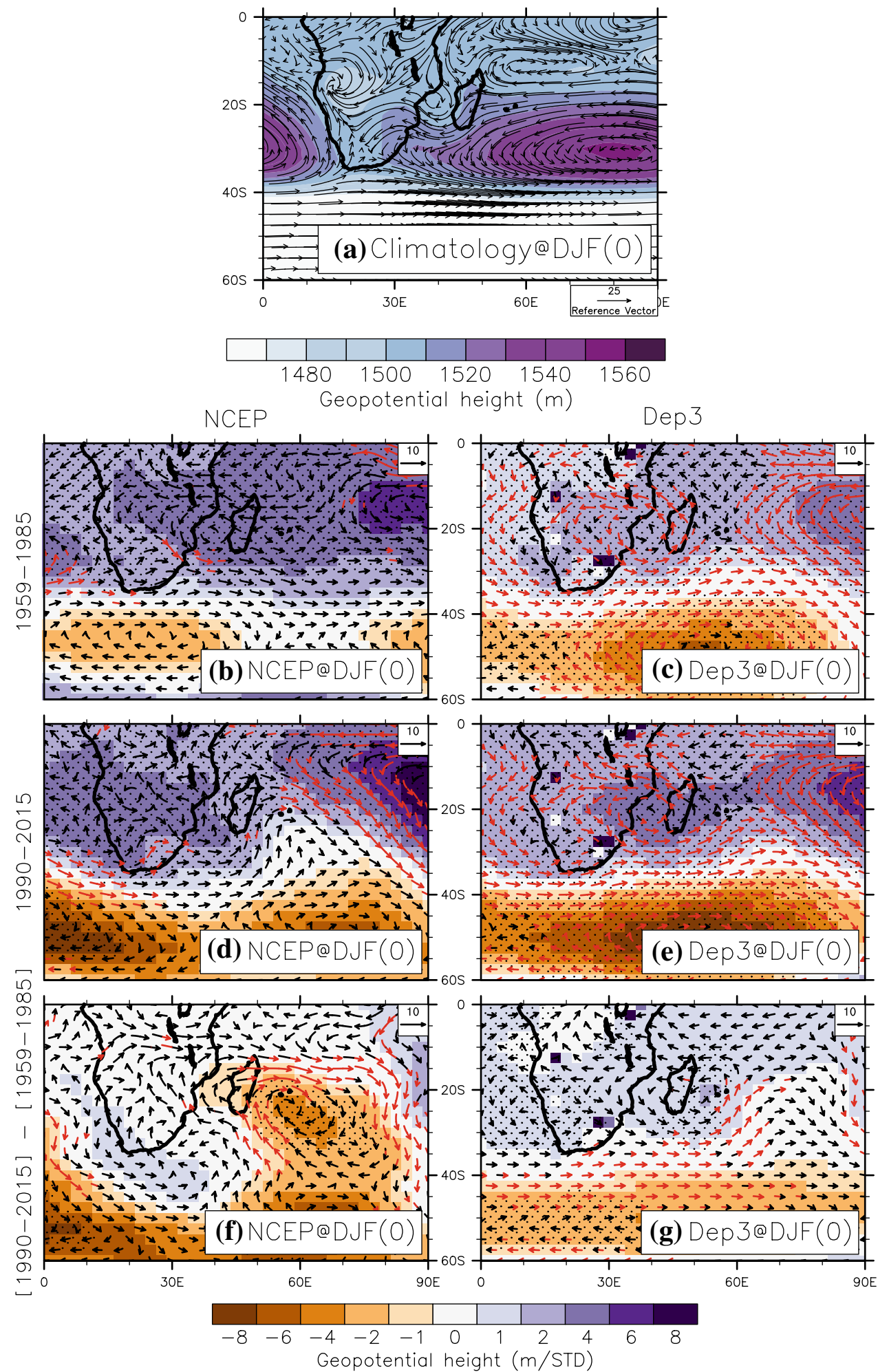

Geopotential height $(\mathrm{m} / \mathrm{STD})$ a decrease in SLP East of South Africa and an increase in SLP over South Africa, and moisture flux divergence over southern Africa, after than before 1990), indicating observed decadal changes in ENSO teleconnection are robust.

\section{Discussion: the role of the decadal warming of the Indian Ocean}

GPCC indicates a change in ENSO impacts on southern African precipitation between two periods, i.e. 1959-1985 
and 1990-2015 (Fig. 7e), due to changes in low-level atmospheric circulation (Fig. 9f). These changes are associated with ENSO leading to a stronger warming of the South Indian Ocean, and to a stronger SIOD over the period 1990-2015 than over the period 1959-1985. These changes in ENSO teleconnections could be due to changes in climate mean state between two epochs, which are shown in Fig. 10.

Relative to the early period the western Pacific Ocean and the Indian Ocean have warmed more strongly than the eastern Pacific Ocean across 1990 (Fig. 10a), leading to an increased Indian Ocean Dipole (Abram et al. 2008). The warming over the equatorial Indian Ocean is associated with divergence at upper-level and convergence over the Pacific Ocean, in a way opposite as the El Nino impact (Fig. 10c). Changes in the mean state could, thus, have modulated the impact of ENSO over the equatorial Indian Ocean (i.e. in velocity potential anomalies) through a change in the atmospheric bridge between the Pacific and South Africa, along with a less pronounced northward displacement of the high pressure systems over and south of South Africa, as observed in Figs. 9f and S15. These changes of the mean state are not reproduced by DePresys3, which simulates a homogeneous temperature increase due to climate change (Fig. 10b). In DePreSys3, the North Atlantic Ocean warms more than the global SAT over the Ocean, leading to an increase in air ascent over the tropical Atlantic Ocean, and subsidence over the western Indian Ocean and southern Africa (Fig. 10d). Therefore, the deficiencies in simulating a shift in ENSO impacts could be due to the inability of DePreSys 3 to simulate the equatorial Indian and the western Pacific Ocean.

We therefore suggest that the decadal change in ENSO teleconnection with southern African precipitation has been modulated by the warming of the Indian Ocean. Although the Indian Ocean SSTs are strongly influenced by ENSO their anomalies can indeed in turn impact the atmospheric circulation leading to temperature changes over the Pacific Ocean (Krishnamurthy and Kirtman 2003; Kug et al. 2006; Xie et al. 2009). It has then been proposed that Indian Ocean warming can cause a rapid termination of El-Niño and a fast transition to La-Niña events by producing an easterly wind stress anomaly over the western edge of Pacific Ocean (Kug et al. 2006; Kug and Kang 2006). As a consequence Wu and Kirtman (2004) have shown that the Indian Ocean modulates the variability of the Pacific Ocean and warm Indian Ocean
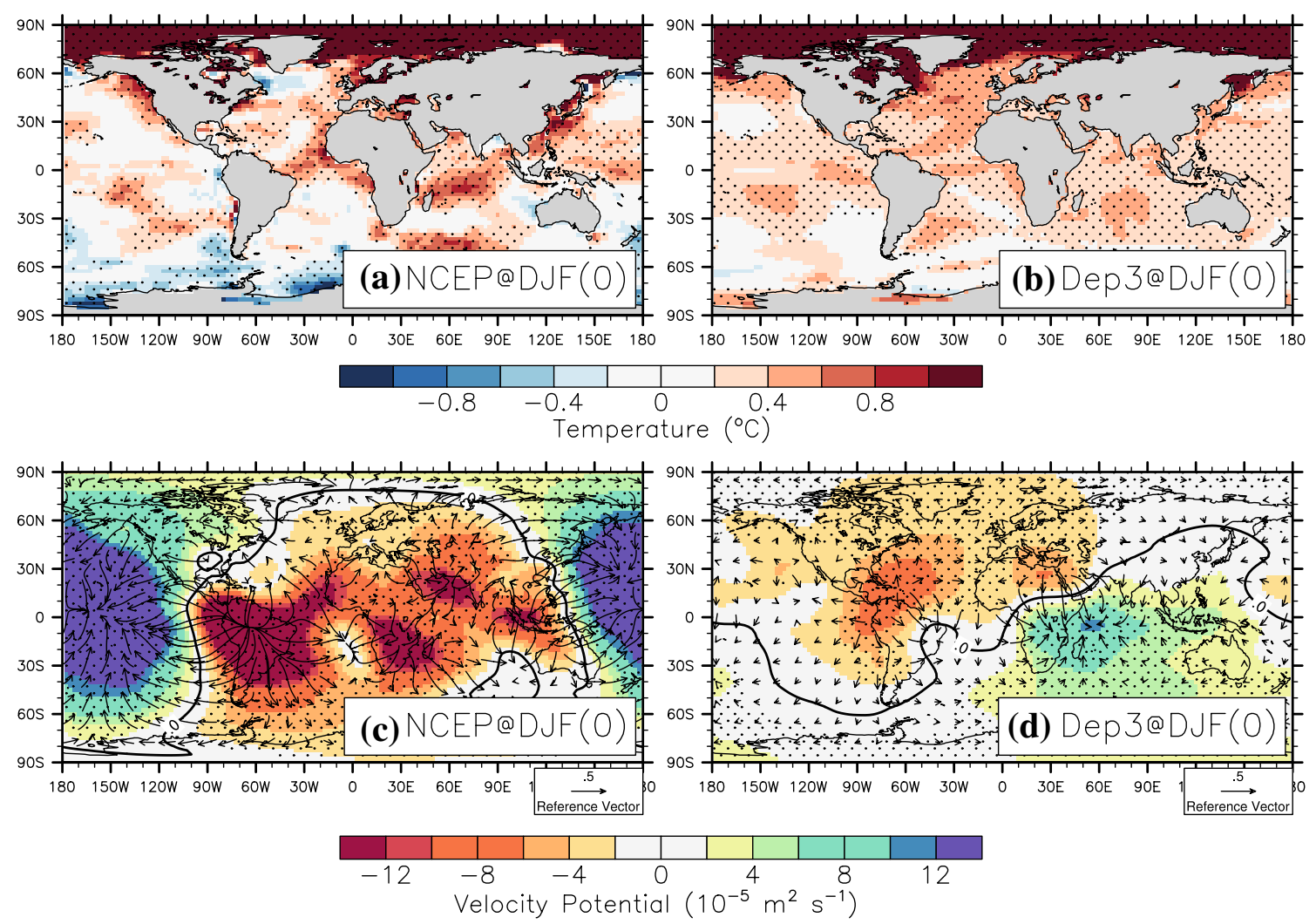

Fig. 10 Observed difference in a surface air temperature $\left({ }^{\circ} \mathrm{C}\right)$ and $\mathbf{c}$ $250 \mathrm{hPa}$ velocity potential $\left(10^{5} \mathrm{~m}^{2} \mathrm{~s}^{-1}\right)$ and divergent wind $\left(\mathrm{m} \mathrm{s}^{-1}\right)$, averaged for the first DJF lead time, and between the period 19902015 and 1959-1985. Simulated difference in b surface air temperature $\left({ }^{\circ} \mathrm{C}\right)$ and $\mathbf{d} 250 \mathrm{hPa}$ velocity potential $\left(10^{5} \mathrm{~m}^{2} \mathrm{~s}^{-1}\right)$ and divergent wind $\left(\mathrm{m} \mathrm{s}^{-1}\right)$, averaged for the first DJF lead time, and between the period 1990-2015 and 1959-1985. Values are considered as significantly different to zero at the $95 \%$ confidence-level according to a two-sided Student t-test. For DePreSys3 results were computed using the ensemble mean 
SST anomalies have been associated with a reduced occurrence of El Niño events. The strong temperature increase of the recent decades has been associated with an increased Indian Ocean temperature variability (Abram et al. 2008) that have led to a weaker influence of ENSO over the Indian Ocean, as highlighted by the recent decreased impact of the Pacific Ocean and increased impact of the Indian Ocean over the Indian Monsoon Rainfall (Ashok et al. 2001).

Reason and Mulenga (1999) pointed out that the change in the temperature gradients over the Indian Ocean (i.e. SIOD) could be responsible for a decrease in sea-level pressure and anomalously strong cyclonic anomalies extending from the coast of Mozambique to southeast Madagascar, along with anomalously strong anticyclonic circulations south of the African landmass, as seen in the Fig. 9f. Thus, we propose that changes in the Indian Ocean and/or over the Pacific Ocean to be responsible for the difference in the ENSO remote impact on southern African precipitation between two periods. Hence the changes in the teleconnections between ENSO and southern African precipitation could result from a change in climate mean state (i.e. mean temperature over the Indian and Pacific Ocean).

\section{Conclusion}

In this paper we evaluate the skill at predicting rainfall over southern Africa up to a year ahead in the UK MetOffice Decadal Prediction System version 3 (DePreSys3), a high-resolution coupled climate prediction system. Specifically, we evaluate a set of 30-member hindcasts, which are initialised over the period 1959-2015 up to a lead time 16 months ahead, and focus on regions over South Africa (SAF; $15-30^{\circ} \mathrm{E} ; 35-25^{\circ} \mathrm{S}$ and $\mathrm{MOZ} ; 20-35^{\circ} \mathrm{E} ; 15-25^{\circ} \mathrm{S}$ ) in the austral summer (DJF). Our main results are as follows.

Over the period 1959-2015 DePreSys3 is able to predict SAF and MOZ summer rainfall at a 2-4 month lead time $(\mathrm{ACC}=0.45)$. DePreSys 3 is also able to predict $\mathrm{MOZ}$ rainfall in the second summer (i.e. 13-15 month lead time, $\mathrm{ACC}=0.37$ ). However, the skill in predicting precipitation is not significant over South Africa for the second summer (ACC $=0.22$, Fig. 1).

The overall skill over southern Africa in DePreSys3 is attributed to accurate predictions of the El-Niño Southern Oscillation (ENSO). The EN3.4 index has an ACC of 0.96 and 0.43 for the first and second DJF, respectively. After subtracting the influence of ENSO on remote rainfall via linear regression, DePreSys 3 is then not able to predict southern African precipitation variability (Fig. S16). Moreover, the inter-member consensus in simulating below-normal (abovenormal) southern Africa precipitation is relatively high during the strong El-Niño (La-Niña) events (Fig. S17), then suggesting then a higher confidence in forecasting precipitation during ENSO events than during neutral years. This result is consistent with findings by Landman and Beraki (2012).

The remote impact of ENSO in DePreSys 3 is consistent with previous studies (e.g. Landman et al. 2001; Reason et al. 2006; Landman and Beraki 2012; Dieppois et al. 2015). DePreSys 3 reproduces the modulation of the WalkerCell circulation associated with ENSO variability. El-Niño leads to an anomalously strong subsidence over the Indian Ocean and southern Africa, a northward shift of the subtropical high-pressure system, a weakening of the Angola Low, and a north-eastward shift of the South Indian Convergence Zone (SICZ) (Mason and Jury 1997; Reason and Mulenga 1999; Cook et al. 2004; Rouault and Richard 2005; Reason and Jagadheesha 2005; Vigaud et al. 2009; Crétat et al. 2012; Ratnam et al. 2014; Dieppois et al. 2015).

The ACC skill in DePreSys 3 is sensitive to the epoch over which it is calculated. For instance, ACC skill in predicting DJF(1) SAF precipitation decreases after the 1980s and skill for MOZ precipitation increases in the 1990s. The exclusion of large ENSO events also impact skill in predicting precipitation. In particular, when large ENSO events are removed, skill in predicting MOZ precipitation for the first summer (DJF(0)) over the period 1990-2015 is high $(\mathrm{ACC}=0.66)$ but not over the period 1959-1985 (ACC=0.19).

The change in skill in different forecast epochs appears to be related to, at least in part, to the non-stationarity of the observed ENSO teleconnection. After 1990, when the skill in MOZ in DJF(0) increases, the impact of ENSO on precipitation over MOZ in observations is found to be larger and more consistent (i.e. stronger regressions and correlations). The larger impact of ENSO over MOZ is consistent with a shift in the location of subtropical high-pressure system location, and with a stronger eastward shift of the SICZ associated with more subsidence over MOZ (Figs. 9f, S12e).

We have demonstrated here that skilful prediction of southern African austral summer precipitation up to a year ahead is possible. Skill over the period 1959-present is associated with DePreSys3's ability to simulate both the SST variability over the tropical Pacific and the Indian Ocean, and the remote impact of ENSO over southern Africa. Predicting the EN3.4 index is crucial, but not sufficient to predict SAF and MOZ precipitation; skill in predicting precipitation varies through time, whereas skill in predicting EN3.4 is consistently high across different epochs. We have related the changes in skill described above to changes in the relationship between ENSO and precipitation over southern Africa before and after 1990. These changes in ENSO teleconnection with southern Africa are consistent with the impact of a warming of the Indian Ocean (Krishnamurthy and Kirtman 2003; Wu and Kirtman 2004; Kug et al. 2006; Kug and Kang 2006; Xie et al. 2009) along with more Central Pacific ENSO (as observed in Kao and Yu 2009), which also affects the precipitation over southern Africa (Ratnam 
et al. 2014; Hoell et al. 2015). However, we cannot rule out that some other aspect of the initialisation (e.g. the quality of the initial state) did not change across different epochs. Nor can we rule out that the change was due to unpredictable climate variability; there is significant variability in the strength of the ENSO teleconnection in DePreSys3 when assessed in the same way as observations (i.e. one ensemble member per year, Fig. S10). However, it is clear that the strength of the relationship between ENSO and southern African rainfall appears to be weaker in DePreSys3 than in observations (Fig. S10).

We assume ENSO as a main source of skill in predicting precipitation since removing its effects reduces the skill substantially. Southern African precipitation are also linked with the Indian SSTs and DePreSys3 exhibit a substantial skill in predicting SIOD for the first summer, which is however largely weaker than for EN3.4 (Fig. 4). SAF and MOZ precipitation variability have also been associated with SST variability over the South Atlantic Ocean in observations (Rouault et al. 2003; Vigaud et al. 2009; Manhique et al. 2015). However, we found that the southern Atlantic Ocean does not strongly affect SAF and MOZ precipitation in DePreSys3 (Fig. S18). In particular the south-eastern Atlantic region, as highlighted in Manhique et al. (2015), does not contribute significantly to the prediction skill for southern African precipitation (Fig. S19). Therefore, we suggest that additional efforts should be devoted to a more process oriented analysis of ENSO predictions, and in understanding how models simulate the global ENSO impacts (see for instance Dieppois et al. 2015) including over different timeperiods and different oceanic and atmospheric background states. Last but not least, a caveat of this study could arise from the non-stationarity in observational measurements over southern Africa from 1990 (see for instance Pitman (2011) and Fig. S1 of Dieppois et al. 2016).

Acknowledgements The authors gratefully acknowledge support from the UK-China Research and Innovation Partnership Fund through the Met Office Climate Science for Service Partnership (CSSP) China as part of the Newton Fund. BD and JR were supported by the Natural Environment Research Council (NERC) via the National Centre for Atmospheric Science (NCAS), and JR was additionally funded by the NERC ACSIS program. We also thank Doug Smith, Leon Hermanson and The Met Office for providing the DePreSys3 output. We thank our three anonymous reviewers for their comments and suggestions.

Open Access This article is distributed under the terms of the Creative Commons Attribution 4.0 International License (http://creativeco mmons.org/licenses/by/4.0/), which permits unrestricted use, distribution, and reproduction in any medium, provided you give appropriate credit to the original author(s) and the source, provide a link to the Creative Commons license, and indicate if changes were made.

\section{References}

Abram NJ, Gagan MK, Cole JE et al (2008) Recent intensification of tropical climate variability in the Indian Ocean. Nat Geosci 1:849

Ashok K, Guan Z, Yamagata T (2001) Impact of the Indian Ocean dipole on the relationship between the Indian monsoon rainfall and ENSO. Geophys Res Lett 28:4499-4502. https://doi. org/10.1029/2001GL013294

Barnston AG, He Y, Glantz MH (1999) Predictive skill of statistical and dynamical climate models in SST forecasts during the 1997-98 El Niño Episode and the 1998 La Niña Onset. Bull Am Meteorol Soc 80:217-243. https://doi.org/10.1175/15200477(1999)080\%3C0217:PSOSAD\%3E2.0.CO;2

Barnston AG, Tippett MK, L'Heureux ML et al (2011) Skill of realtime seasonal ENSO model predictions during 2002-11: is our capability increasing? Bull Am Meteorol Soc 93:631-651. https://doi.org/10.1175/BAMS-D-11-00111.1

Behera SK, Yamagata T (2001) Subtropical SST dipole events in the southern Indian Ocean. Geophys Res Lett 28:327-330. https:// doi.org/10.1029/2000GL011451

Bellucci A, Gualdi S, Masina S et al (2013) Decadal climate predictions with a coupled OAGCM initialized with oceanic reanalyses. Clim Dyn 40:1483-1497. https://doi.org/10.1007/s0038 2-012-1468-z

Beraki AF, DeWitt DG, Landman WA, Olivier C (2013) Dynamical seasonal climate prediction using an ocean-atmosphere coupled climate model developed in partnership between South Africa and the IRI. J Clim 27:1719-1741. https://doi. org/10.1175/JCLI-D-13-00275.1

Bernard B, Madec G, Penduff T et al (2006) Impact of partial steps and momentum advection schemes in a global ocean circulation model at eddy-permitting resolution. Ocean Dyn 56:543567. https://doi.org/10.1007/s10236-006-0082-1

Best MJ, Pryor M, Clark DB et al (2011) The joint UK land environment simulator (JULES), model description-part 1: energy and water fluxes. Geosci Model Dev 4:677-699. https://doi. org/10.5194/gmd-4-677-2011

Chikamoto Y, Kimoto M, Ishii M et al (2013) An overview of decadal climate predictability in a multi-model ensemble by climate model MIROC. Clim Dyn 40:1201-1222. https://doi. org/10.1007/s00382-012-1351-y

Christensen JH, Hewitson B, Busuioc A et al (2007) Regional climate projections. Climate change, 2007: The physical science basis. In: Contribution of working group I to the Fourth Assessment Report of the Intergovernmental Panel on Climate Change. University Press, Cambridge, Chap. 11, pp 847-940

Compo GP, Whitaker JS, Sardeshmukh PD (2006) Feasibility of a 100-year reanalysis using only surface pressure data. Bull Am Meteorol Soc 87:175-190. https://doi.org/10.1175/ BAMS-87-2-175

Cook KH (2000) The South Indian convergence zone and interannual rainfall variability over Southern Africa. J Clim 13:3789-3804. https://doi.org/10.1175/1520-0442(2000)013\%3C3789:TSICZ A\%3E2.0.CO;2

Cook C, Reason CJC, Hewitson BC (2004) Wet and dry spells within particularly wet and dry summers in the South African summer rainfall region. Clim Res 26:17-31

Crétat J, Richard Y, Pohl B et al (2012) Recurrent daily rainfall patterns over South Africa and associated dynamics during the core of the austral summer. Int J Climatol 32:261-273. https://doi. org/10.1002/joc. 2266

Crétat J, Pohl B, Dieppois B et al (2018) The Angola Low: relationship with southern African rainfall and ENSO. Clim Dyn. https://doi. org/10.1007/s00382-018-4222-3 
Crimp SJ, Lutjeharms JRE, Mason SJ (1998) Sensitivity of a tropicaltemperate trough to sea-surface temperature anomalies in the Agulhas retroflection region. Water SA 24:93-101

Day JJ, Hawkins E, Tietsche S (2014) Will Arctic sea ice thickness initialization improve seasonal forecast skill? Geophys Res Lett 41:7566-7575. https://doi.org/10.1002/2014GL061694

Dee DP, Uppala SM, Simmons AJ et al (2011) The ERA-Interim reanalysis: configuration and performance of the data assimilation system. Q J R Meteorol Soc 137:553-597. https://doi. org/10.1002/qj.828

Dieppois B, Rouault M, New M (2015) The impact of ENSO on Southern African rainfall in CMIP5 ocean atmosphere coupled climate models. Clim Dyn 45:2425-2442. https://doi.org/10.1007/s0038 2-015-2480-X

Dieppois B, Pohl B, Rouault M et al (2016) Interannual to interdecadal variability of winter and summer southern African rainfall, and their teleconnections. J Geophys Res Atmos 121:6215-6239. https://doi.org/10.1002/2015JD024576

Doblas-Reyes FJ, Andreu-Burillo I, Chikamoto Y et al (2013a) Initialized near-term regional climate change prediction. Nat Commun 4:1715. https://doi.org/10.1038/ncomms2704

Doblas-Reyes FJ, García-Serrano J, Lienert F et al (2013b) Seasonal climate predictability and forecasting: status and prospects. Wiley Interdiscip Rev Clim Chang 4:245-268. https://doi. org/10.1002/wcc. 217

Douville H, Chauvin F (2000) Relevance of soil moisture for seasonal climate predictions: a preliminary study. Clim Dyn 16:719-736. https://doi.org/10.1007/s003820000080

Dunstone N, Smith D, Scaife A et al (2016) Skilful predictions of the winter North Atlantic Oscillation one year ahead. Nat Geosci 9:809-814. https://doi.org/10.1038/ngeo2824

Dunstone N, Smith D, Scaife A et al (2018) Skilful seasonal predictions of summer European rainfall. Geophys Res Lett 45:3246-3254. https://doi.org/10.1002/2017GL076337

Dyer TG, Tyson PD (1977) Estimating above and below normal rainfall periods over South Africa, 1972-2000. J Appl Meteor 16:145-147. https://doi.org/10.1175/15200450(1977)016<0145:EAABNR > 2.0.CO;2

Fauchereau N, Pohl B, Reason CJC et al (2009) Recurrent daily OLR patterns in the Southern Africa/Southwest Indian Ocean region, implications for South African rainfall and teleconnections. Clim Dyn 32:575-591. https://doi.org/10.1007/s00382-008-0426-2

Gaetani M, Mohino E (2013) Decadal prediction of the Sahelian precipitation in CMIP5 simulations. J Clim 26:7708-7719. https:// doi.org/10.1175/JCLI-D-12-00635.1

Gonzalez PLM, Goddard L (2016) Long-lead ENSO predictability from CMIP5 decadal hindcasts. Clim Dyn 46:3127-3147. https ://doi.org/10.1007/s00382-015-2757-0

Harris I, Jones PD, Osborn TJ, Lister DH (2014) Updated high-resolution grids of monthly climatic observations - the CRU TS3.10 dataset. Int J Climatol 34:623-642. https://doi.org/10.1002/ joc. 3711

Harrison (1984) A generalized classification of South African summer rain-bearing synoptic systems. J Climatol 4:547-560. https://doi. org/10.1002/joc. 3370040510

Hart NCG, Reason CJC, Fauchereau N (2012) Building a tropicalextratropical cloud band Metbot. Mon Weather Rev 140:40054016. https://doi.org/10.1175/MWR-D-12-00127.1

Hart NCG, Reason CJC, Fauchereau N (2013) Cloud bands over southern Africa: seasonality, contribution to rainfall variability and modulation by the MJO. Clim Dyn 41:1199-1212. https://doi. org/10.1007/s00382-012-1589-4

Hewitson BC, Crane RG (2006) Consensus between GCM climate change projections with empirical downscaling: precipitation downscaling over South Africa. Int J Climatol 26:1315-1337. https://doi.org/10.1002/joc.1314
Hoell A, Cheng L (2018) Austral summer Southern Africa precipitation extremes forced by the El Ni\{ñ $\}_{0}-$ Southern oscillation and the subtropical Indian Ocean dipole. Clim Dyn 50:3219-3236. https ://doi.org/10.1007/s00382-017-3801-z

Hoell A, Funk C, Magadzire T et al (2015) El Ni $\{\tilde{n}\}_{0}-$ southern oscillation diversity and Southern Africa teleconnections during Austral suMMER. Clim Dyn 45:1583-1599. https://doi.org/10.1007/ s00382-014-2414-z

Hoell A, Funk C, Zinke J, Harrison L (2017a) Modulation of the Southern Africa precipitation response to the El Niño Southern Oscillation by the subtropical. Indian Ocean Dipole Clim Dyn 48:2529-2540. https://doi.org/10.1007/s00382-016-3220-6

Hoell A, Gaughan AE, Shukla S, Magadzire T (2017b) The hydrologic effects of synchronous El Niño-Southern oscillation and subtropical Indian ocean dipole events over Southern Africa. J Hydrometeorol 18:2407-2424. https://doi.org/10.1175/JHM-D-16-0294.1

Howard E, Washington R (2018) Characterizing the synoptic expression of the angola low. J Clim 31:7147-7165. https://doi. org/10.1175/JCLI-D-18-0017.1

Hunke EC, Lipscomb WH (2004) The Los Alamos sea ice model, documentation and software. Version 3.1. Tech. rep. Los Alamos National Laboratory, NM. https://csdms.colorado.edu/w/image s/CICE_documentation_and_software_user\%27s_manual.pdf

ICPO (2011) Data and bias correction for decadal climate predictions. International CLIVAR project office publication series 150:5. http://www.wcrp-climate.org/decadal/references/DCPP_Bias_ Correction.pdf

Imada Y, Tatebe H, Ishii M et al (2015) Predictability of two types of El Niño assessed using an extended seasonal prediction system by MIROC. Mon Weather Rev 143:4597-4617. https://doi. org/10.1175/MWR-D-15-0007.1

Kanamitsu M, Ebisuzaki W, Woollen J et al (2002) NCEP-DOE AMIPII reanalysis (R-2). Bull Am Meteorol Soc 83:1631-1643. https ://doi.org/10.1175/BAMS-83-11-1631

Kao H-Y, Yu J-Y (2009) Contrasting Eastern-Pacific and centralPacific types of ENSO. J Clim 22:615-632. https://doi. org/10.1175/2008JCLI2309.1

Karspeck A, Yeager S, Danabasoglu G, Teng H (2015) An evaluation of experimental decadal predictions using CCSM4. Clim Dyn 44:907-923. https://doi.org/10.1007/s00382-014-2212-7

Kessler WS (2002) Is ENSO a cycle or a series of events? Geophys Res Lett 29:40-44. https://doi.org/10.1029/2002GL015924 doi

Klein SA, Soden BJ, Lau N-C (1999) Remote sea surface temperature variations during ENSO: evidence for a tropical atmospheric bridge. J Clim 12:917-932. https://doi.org/10.1175/15200442(1999)012\%3C0917:RSSTVD\%3E2.0.CO;2

Kosaka Y, Xie S-P (2013) Recent global-warming hiatus tied to equatorial Pacific surface cooling. Nature 501:403-407

Krishnamurthy V, Kirtman BP (2003) Variability of the Indian Ocean: relation to monsoon and ENSO. Q J R Meteorol Soc 129:16231646. https://doi.org/10.1256/qj.01.166

Kug J-S, Kang I-S (2006) Interactive feedback between ENSO and the Indian Ocean. J Clim 19:1784-1801. https://doi.org/10.1175/ JCLI3660.1

Kug J-S, Li T, An S-I et al (2006) Role of the ENSO-Indian Ocean coupling on ENSO variability in a coupled GCM. Geophys Res Lett. https://doi.org/10.1029/2005GL024916

Landman WA, Beraki A (2012) Multi-model forecast skill for midsummer rainfall over southern Africa. Int J Climatol 32:303-314. https://doi.org/10.1002/joc.2273

Landman WA, Mason SJ, Tyson PD, Tennant WJ (2001) Retro-active skill of multi-tiered forecasts of summer rainfall over southern Africa. Int J Climatol 21:1-19. https://doi.org/10.1002/joc.592

Lindesay JA (1988) South African rainfall, the Southern oscillation and a Southern Hemisphere semi-annual cycle. J Climatol 8:17-30. https://doi.org/10.1002/joc.3370080103 
Lyon B, Mason SJ (2007) The 1997-98 summer rainfall season in Southern Africa. Part I: observations. J Clim 20:5134-5148. https://doi.org/10.1175/JCLI4225.1

Lyon B, Mason SJ (2009) The 1997/98 summer rainfall season in Southern Africa. Part II: model simulations and coupled model forecasts. J Clim 22:3802-3818. https://doi.org/10.1175/2009J CLI2600.1

MacLachlan C, Arribas A, Peterson KA et al (2015) Global seasonal forecast system version 5 (GloSea5): a high-resolution seasonal forecast system. Q J R Meteorol Soc 141:1072-1084. https://doi. org/10.1002/qj.2396

Macron C, Pohl B, Richard Y, Bessafi M (2013) How do tropical temperate troughs form and develop over Southern Africa? J Clim 27:1633-1647. https://doi.org/10.1175/JCLI-D-13-00175.1

Madec G (2008) NEMO ocean engine. Note du Pole de modélisation, Institut Pierre-Simon Laplace (IPSL), France No 27, ISSN No 1288-1619. https://www.nemo-ocean.eu/wp-content/uploads/ NEMO_book.pdf

Malherbe J, Dieppois B, Maluleke P et al (2016) South African droughts and decadal variability. Nat Hazards 80:657-681. https ://doi.org/10.1007/s11069-015-1989-y

Manhique AJ, Reason CJC, Silinto B et al (2015) Extreme rainfall and floods in southern Africa in January 2013 and associated circulation patterns. Nat Hazards 77:679-691. https://doi.org/10.1007/ s11069-015-1616-y

Mantua NJ, Hare SR (2002) The Pacific Decadal Oscillation. J Oceanogr 58:35-44. https://doi.org/10.1023/A:1015820616384

Mantua NJ, Hare SR, Zhang Y et al (1997) A pacific interdecadal climate oscillation with impacts on Salmon production. Bull Am Meteorol Soc 78:1069-1079. https://doi.org/10.1175/15200477(1997)078\%3C1069:APICOW\%3E2.0.CO;2

Mason SJ, Goddard L (2001) Probabilistic precipitation anomalies associated with ENSO. Bull Am Meteorol Soc 82:619-638. https://doi.org/10.1175/1520-0477(2001)082\%3C0619:PPAAW E\%3E2.3.CO;2

Mason SJ, Jury MR (1997) Climatic variability and change over southern Africa: a reflection on underlying processes. Prog Phys Geogr 21:23-50. https://doi.org/10.1177/030913339702100103

Matarira CH (1990) Drought over Zimbabwe in a regional and global context. Int J Climatol 10:609-625

Matei D, Pohlmann H, Jungclaus J et al (2012) Two tales of initializing decadal climate prediction experiments with the ECHAM5/ MPI-OM model. J Clim 25:8502-8523. https://doi.org/10.1175/ JCLI-D-11-00633.1

Meehl GA, Goddard L, Murphy J et al (2009) Decadal prediction. Bull Am Meteorol Soc 90:1467-1485. https://doi.org/10.1175/2009B AMS2778.1

Meehl GA, Teng H, Arblaster JM (2014) Climate model simulations of the observed early-2000 s hiatus of global warming. Nat Clim Chang 4:898-902

Megann A, Storkey D, Aksenov Y et al (2014) GO5.0: the joint NERCMet Office NEMO global ocean model for use in coupled and forced applications. Geosci Model Dev 7:1069-1092. https://doi. org/10.5194/gmd-7-1069-2014

Mills CM, Walsh JE (2013) Seasonal variation and spatial patterns of the atmospheric component of the Pacific decadal oscillation. J Clim 26:1575-1594. https://doi.org/10.1175/JCLI-D-12-00264.1

Minobe S (2000) Spatio-temporal structure of the pentadecadal variability over the North Pacific. Prog Oceanogr 47:381-408. https ://doi.org/10.1016/S0079-6611(00)00042-2

Mochizuki T, Chikamoto Y, Kimoto M et al (2012) Decadal prediction using a recent series of MIROC global climate models. J Meteorol Soc Japan 90A:373-383. https://doi.org/10.2151/ jmsj.2012-A22

Mohino E, Keenlyside N, Pohlmann H (2016) Decadal prediction of Sahel rainfall: where does the skill (or lack thereof) come from? Clim Dyn 47:3593-3612. https://doi.org/10.1007/s0038 2-016-3416-9

Monerie P-A, Coquart L, Maisonnave É et al (2017) Decadal prediction skill using a high-resolution climate model. Clim Dyn. https:// doi.org/10.1007/s00382-017-3528-x

Morioka Y, Engelbrecht F, Behera SK (2015) Potential sources of decadal climate variability over Southern Africa. J Clim 28:86958709. https://doi.org/10.1175/JCLI-D-15-0201.1

Munday C, Washington R (2017) Circulation controls on southern African precipitation in coupled models: the role of the Angola Low. J Geophys Res Atmos 122:861-877. https://doi. org/10.1002/2016JD025736

Nicholson SE, Kim Je (1997) The relationship of the El Niño-Southern oscillation to African rainfall. Int J Climatol 17:117-135. https ://doi.org/10.1002/(SICI)1097-0088(199702)17:2\%3C117::AIDJOC84\%3E3.0.CO;2-O

Nikulin G, Jones C, Giorgi F et al (2012) Precipitation climatology in an ensemble of CORDEX-Africa regional climate simulations. J Clim 25:6057-6078. https://doi.org/10.1175/JCLI-D-11-00375.1

O'Reilly CH, Heatley J, MacLeod D et al (2017) Variability in seasonal forecast skill of Northern Hemisphere winters over the twentieth century. Geophys Res Lett 44:5729-5738. https:// doi.org/10.1002/2017GL073736

Orsolini YJ, Senan R, Balsamo G et al (2013) Impact of snow initialization on sub-seasonal forecasts. Clim Dyn 41:1969-1982. https://doi.org/10.1007/s00382-013-1782-0

Philippon N, Rouault M, Richard Y, Favre A (2012) The influence of ENSO on winter rainfall in South Africa. Int J Climatol 32:2333-2347. https://doi.org/10.1002/joc.3403

Pitman WV (2011) Overview of water resource assessment in South Africa: current state and future challenges. Water SA 37:659-664

Pohlmann H, Jungclaus JH, Köhl A et al (2009) Initializing decadal climate predictions with the GECCO oceanic synthesis: effects on the North Atlantic. J Clim 22:3926-3938. https:// doi.org/10.1175/2009JCLI2535.1

Pohl B, Dieppois B, Crétat J, Lawler D, Rouault M (2018) From synoptic to interdecadal variability in Southern African rainfall: toward a unified view across time scales. J Climate 31:5845-5872

Power S, Casey T, Folland C et al (1999) Inter-decadal modulation of the impact of ENSO on Australia. Clim Dyn 15:319-324. https://doi.org/10.1007/s003820050284

Ratna SB, Behera S, Ratnam JV et al (2013) An index for tropical temperate troughs over southern Africa. Clim Dyn 41:421441. https://doi.org/10.1007/s00382-012-1540-8

Ratnam JV, Behera SK, Masumoto Y, Yamagata T (2014) Remote effects of El Niño and modoki events on the Austral summer precipitation of Southern Africa. J Clim 27:3802-3815. https ://doi.org/10.1175/JCLI-D-13-00431.1

Rayner NA, Parker DE, Horton EB et al (2003) Global analyses of sea surface temperature, sea ice, and night marine air temperature since the late nineteenth century. J Geophys Res 108:4407. https://doi.org/10.1029/2002JD002670

Reason CJC, Jagadheesha D (2005) A model investigation of recent ENSO impacts over southern Africa. Meteorol Atmos Phys 89:181-205. https://doi.org/10.1007/s00703-005-0128-9

Reason CJC, Mulenga H (1999) Relationships between South African rainfall and SST anomalies in the southwest Indian Ocean. Int J Climatol 19:1651-1673

Reason CJC, Rouault M (2002) ENSO-like decadal variability and South African rainfall. Geophys Res Lett 29:14-16. https://doi. org/10.1029/2002GL014663

Reason CJC, Landman W, Tennant W (2006) Seasonal to decadal prediction of southern African climate and its links with variability of the Atlantic Ocean. Bull Am Meteorol Soc 87:941955. https://doi.org/10.1175/BAMS-87-7-941 
Richard Y, Trzaska S, Roucou P, Rouault M (2000) Modification of the southern African rainfall variability/ENSO relationship since the late 1960s. Clim Dyn 16:883-895. https://doi. org/10.1007/s003820000086

Richard Y, Fauchereau N, Poccard I et al (2001) 20th century droughts in southern Africa: spatial and temporal variability, teleconnections with oceanic and atmospheric conditions. Int $\mathbf{J}$ Climatol 21:873-885. https://doi.org/10.1002/joc.656

Robson J, Polo I, Hodson DLR et al (2017) Decadal prediction of the North Atlantic subpolar gyre in the HiGEM high-resolution climate model. Clim Dyn. https://doi.org/10.1007/s0038 2-017-3649-2

Ropelewski CF, Halpert MS (1987) Global and Regional scale precipitation patterns associated with the El Niño/Southern oscillation. Mon Weather Rev 115:1606-1626. https:// doi.org/10.1175/1520-0493(1987)115\%3C1606:GARSP $\mathrm{P} \% 3 \mathrm{E} 2.0 . \mathrm{CO} ; 2$

Ropelewski CF, Halpert MS (1989) Precipitation patterns associated with the high index phase of the southern oscillation. J Clim 2:268-284. https://doi.org/10.1175/1520-0442(1989)002\%3C026 8:PPAWTH\%3E2.0.CO;2

Rouault M, Richard Y (2005) Intensity and spatial extent of droughts in southern Africa. Geophys Res Lett. https://doi. org/10.1029/2005GL022436

Rouault M, Florenchie P, Fauchereau N, Reason CJC (2003) South East tropical Atlantic warm events and southern African rainfall. Geophys Res Lett. https://doi.org/10.1029/2002GL014840

Schneider U, Becker A, Finger P et al (2014) GPCC's new land surface precipitation climatology based on quality-controlled in situ data and its role in quantifying the global water cycle. Theor Appl Climatol 115:15-40. https://doi.org/10.1007/s00704-013-0860-x

Shaffrey LC, Hodson D, Robson J et al (2017) Decadal predictions with the HiGEM high resolution global coupled climate model: description and basic evaluation. Clim Dyn 48:297-311. https:// doi.org/10.1007/s00382-016-3075-x

Sheen KL, Smith DM, Dunstone NJ et al (2017) Skilful prediction of Sahel summer rainfall on inter-annual and multi-year timescales. Nature Commun 8:14966

Smith DM, Murphy JM (2007) An objective ocean temperature and salinity analysis using covariances from a global climate model. J Geophys Res 112:C02022. https://doi.org/10.1029/2005JC0031 72

Smith DM, Allan RP, Coward AC et al (2015) Earth's energy imbalance since 1960 in observations and CMIP5 models. Geophys Res Lett 42:1205-1213. https://doi.org/10.1002/2014GL062669

Taylor KE, Stouffer RJ, Meehl GA (2012) An overview of CMIP5 and the experiment design. Bull Am Meteorol Soc 93:485-498

Todd M, Washington R (1999) Circulation anomalies associated with tropical-temperate troughs in southern Africa and the south west. Indian Ocean Clim Dyn 15:937-951. https://doi.org/10.1007/ s003820050323

Tyson PD (1981) Atmospheric circulation variations and the occurrence of extended wet and dry spells over Southern Africa. J Climatol 1:115-130. https://doi.org/10.1002/joc.3370010203

Valcke S (2013) The OASIS3 coupler: a European climate modelling community software. Geosci Model Dev 6:373-388. https://doi. org/10.5194/gmd-6-373-2013 van den Hurk B, Doblas-Reyes F, Balsamo G et al (2012) Soil moisture effects on seasonal temperature and precipitation forecast scores in Europe. Clim Dyn 38:349-362. https://doi.org/10.1007/s0038 2-010-0956-2

Vigaud N, Richard Y, Rouault M, Fauchereau N (2009) Moisture transport between the South Atlantic Ocean and southern Africa: relationships with summer rainfall and associated dynamics. Clim Dyn 32:113-123. https://doi.org/10.1007/s00382-008-0377-7

Vizy EK, Cook KH, Chimphamba J, McCusker B (2015) Projected changes in Malawi's growing season. Clim Dyn 45:1673-1698. https://doi.org/10.1007/s00382-014-2424-x

Walters DN, Williams KD, Boutle IA et al (2014) The met office unified model global atmosphere 4.0 and JULES global land 4.0 configurations. Geosci Model Dev 7:361-386. https://doi. org/10.5194/gmd-7-361-2014

Washington R, Preston A (2006) Extreme wet years over southern Africa: Role of Indian Ocean sea surface temperatures. J Geophys Res Atmos. https://doi.org/10.1029/2005JD006724

Watanabe M, Kamae Y, Yoshimori M et al (2013) Strengthening of ocean heat uptake efficiency associated with the recent climate hiatus. Geophys Res Lett 40:3175-3179. https://doi.org/10.1002/ grl.50541

Weisheimer A, Schaller N, O'Reilly C et al (2017) Atmospheric seasonal forecasts of the twentieth century: multi-decadal variability in predictive skill of the winter North Atlantic Oscillation (NAO) and their potential value for extreme event attribution. Q J R Meteorol Soc 143:917-926. https://doi.org/10.1002/qj.2976

Williams KD, Harris CM, Bodas-Salcedo A et al (2015) The Met Office Global Coupled model 2.0 (GC2) configuration. Geosci Model Dev 8:1509-1524. https://doi.org/10.5194/gmd-8-1509-2015

Willmott CJ, Matsuura K (2001) Terrestrial air temperature and precipitation: monthly and annual time series (1950-1999). http://clima te.geog.udel.edu/ climate/html_pages/README.ghen_ts2.html.

Wu R, Kirtman BP (2004) Understanding the Impacts of the Indian Ocean on ENSO Variability in a Coupled GCM. J Clim 17:40194031. https://doi.org/10.1175/1520-0442(2004)017\%3C401 9:UTIOTI\%3E2.0.CO;2

Xie S-P, Hu K, Hafner J et al (2009) Indian Ocean capacitor effect on Indo-Western Pacific climate during the summer following El Niño. J Clim 22:730-747. https://doi.org/10.1175/2008JCLI25 44.1

Yeager S, Karspeck A, Danabasoglu G et al (2012) A decadal prediction case study: late Twentieth-century North Atlantic ocean heat content. J Clim 25:5173-5189. https://doi.org/10.1175/ JCLI-D-11-00595.1

Yeager SG, Danabasoglu G, Rosenbloom N et al (2018) Predicting near-term changes in the earth system: a large ensemble of initialized decadal prediction simulations using the community earth system model. Bull Am Meteorol Soc. https://doi.org/10.1175/ BAMS-D-17-0098.1

Zhang Y, Wallace JM, Battisti DS (1997) ENSO-like interdecadal variability: 1900-93. J Clim 10:1004-1020. https://doi. org/10.1175/1520-0442(1997)010\%3C1004:ELIV\%3E2.0.CO;2

Zhong A, Hendon HH, Alves O (2005) Indian Ocean variability and its association with ENSO in a global coupled model. J Clim 18:3634-3649. https://doi.org/10.1175/JCLI3493.1 